OPEN ACCESS

Edited by:

Tadashi Kimura

Osaka University Hospital, Japan

Reviewed by:

Tomoaki lkeda,

Mie University, Japan

Gian Carlo Di Renzo,

Hospital of Santa Maria

della Misericordia in Perugia, Italy

*Correspondence:

Atul Malhotra

atul.malhotra@monash.edu

tThese authors have contributed equally to this work

Specialty section:

This article was submitted to

Reproduction,

a section of the journal

Frontiers in Endocrinology

Received: 30 October 2018

Accepted: 22 January 2019

Published: 07 February 2019

Citation:

Malhotra A, Allison $B J$

Castillo-Melendez M, Jenkin G,

Polglase GR and Miller SL (2019)

Neonatal Morbidities of Fetal Growth

Restriction: Pathophysiology and Impact. Front. Endocrinol. 10:55 doi: 10.3389/fendo.2019.00055

\section{Neonatal Morbidities of Fetal Growth Restriction: Pathophysiology and Impact}

\author{
Atul Malhotra ${ }^{1,2,3 * t}$, Beth J. Allison ${ }^{2,4 t}$, Margie Castillo-Melendez ${ }^{2,4}$, Graham Jenkin ${ }^{2,4}$, \\ Graeme R. Polglase ${ }^{2,4}$ and Suzanne L. Miller ${ }^{2,4}$
}

${ }^{1}$ Monash Newborn, Monash Children's Hospital, Melbourne, VIC, Australia, ${ }^{2}$ The Ritchie Centre, Hudson Institute of Medical Research, Melbourne, VIC, Australia, ${ }^{3}$ Department of Paediatrics, Monash University, Melbourne, VIC, Australia

${ }^{4}$ Department of Obstetrics and Gynaecology, Monash University, Melbourne, VIC, Australia

Being born small lays the foundation for short-term and long-term implications for life. Intrauterine or fetal growth restriction describes the pregnancy complication of pathological reduced fetal growth, leading to significant perinatal mortality and morbidity, and subsequent long-term deficits. Placental insufficiency is the principal cause of FGR, which in turn underlies a chronic undersupply of oxygen and nutrients to the fetus. The neonatal morbidities associated with FGR depend on the timing of onset of placental dysfunction and growth restriction, its severity, and the gestation at birth of the infant. In this review, we explore the pathophysiological mechanisms involved in the development of major neonatal morbidities in FGR, and their impact on the health of the infant. Fetal cardiovascular adaptation and altered organ development during gestation are principal contributors to postnatal consequences of FGR. Clinical presentation, diagnostic tools and management strategies of neonatal morbidities are presented. We also present information on the current status of targeted therapies. A better understanding of neonatal morbidities associated with FGR will enable early neonatal detection, monitoring and management of potential adverse outcomes in the newborn period and beyond.

Keywords: IUGR, FGR, bronchopulmonary dysplasia, cardiac, brain injury, necrotizing enterocolitis

\section{OVERVIEW AND DESCRIPTION}

Fetal growth restriction (FGR) describes the fetus that does not grow to its expected biological potential in utero, and is a relatively common complication of pregnancy. True FGR, as compared to constitutional smallness, is a pathological condition wherein the placental fails to deliver an adequate supply of oxygen and nutrients to the developing fetus, termed placental insufficiency. As a consequence, fetal growth becomes stunted. It is only in the last several years that consensus definitions for pathological FGR have been developed (1), but it remains that many cases of FGR in utero remain undetected, and therefore the neonatal description of small for gestational age (SGA) continues to be a useful and necessary proxy for FGR (2). Traditionally, an estimated fetal weight or abdominal circumference of less than the 10th centile for the population at a given gestational age was considered highly suggestive of FGR. However this broad description of SGA includes the many infants $(\sim 20 \%)$ that are born small, but are otherwise healthy (2). Accordingly, consensus definitions for FGR now incorporate Doppler indices of placental function/ dysfunction during pregnancy (1), to provide a more robust assessment of pathological fetal growth restriction. 
Clear and well-defined guidelines for description of FGR subsequent to placental insufficiency are important for two broad reasons, (i) early identification of FGR flags infants who are at significantly elevated risk for neonatal complications, and (ii) early identification of infants with FGR who would benefit from intervention(s) to improve outcomes. The etiology of many adverse consequences of FGR arise in utero from fetal hypoxia and nutrient deprivation secondary to placental dysfunction, with fetal hemodynamic adaptations in utero laying the foundation for altered organ structure and function in the neonatal period and beyond.

\section{ETIOLOGY AND UTEROPLACENTAL FACTORS}

The basic determinants of fetal growth are the individual's genetic makeup, nutrient availability from the mother, and environmental factors, coupled with the capacity of the placenta to adequately transfer nutrients and oxygen to the fetus, and endocrine modulation of these interactions (3, 4). Reduced fetal growth, and subsequent pathological FGR, can be caused by maternal factors (e.g., under nutrition, hypertension, preeclampsia), fetal (chromosomal abnormalities, multiple fetuses) or placental factors (5), however in the majority of cases, FGR results from placental dysfunction (6). Here, the term placental insufficiency is broadly used to describe reduced transfer of oxygen and nutrients to the fetus, with adverse effects on fetal development. Antecedents of placental insufficiency can include maternal malnutrition and hypertension, but in up to $60 \%$ of cases the placental insufficiency is idiopathic, wherein there is a physiological deficiency in the remodeling of uterine and placental spiral arteries resulting in restricted uteroplacental perfusion (7).

Abnormalities in placental function provide a primary clinical indicator that transfer of oxygen and nutrients is suboptimal, and fetal growth may be adversely affected. In the fetus, placental insufficiency is characterized by preferential blood flow redistribution to the vital organs (brain, myocardium, and adrenal glands), while other organs, including the gastrointestinal tract, skin, and others may be deprived of sufficient blood flow. This fetal redistribution of blood flow occurs as a direct result of hypoxia, and can be detected as altered umbilical, uterine and/or middle cerebral artery Doppler flows (8). Large population studies of small but otherwise healthy infants at birth (Apgar $\geq$ 7 at 5 min of life) demonstrates that severely growth restricted infants at the third birth weight centile are indeed chronically hypoxic; umbilical vein median $\mathrm{pO}_{2} 13 \mathrm{mmHg}$ (FGR) versus 26 mmHg (normally grown infants), and median $\mathrm{SaO}_{2} 16$ vs. $55 \%$ respectively $(9,10)$.

In addition to the fundamental roles of oxygen and glucose for development, fetal growth is dependent on a number of key anabolic hormones-placental, pancreatic, thyroid, adrenal and pituitary hormones-any disruption in these can also lead to FGR $(11,12)$. The insulin-like growth factors -I and -II (IGF-I and IGF-II) are both proposed to play central roles in normal fetal growth, stimulating fetal cell proliferation, differentiation, protein and glycogen synthesis, where these actions are mediated via their receptors and the IGF-binding proteins (IGFBPs). The two IGFs are detected in the fetal circulation in early gestation, and in particular it is noted that decreased serum IGF-1 is correlated with reduced fetal growth $(3,13)$. IGF-1 also has a central role in brain growth, white matter development and brain connectivity (14). Pregnancyassociated plasma protein-A (PAPP-A), secreted by the placental decidua, cleaves IGFBP-4, which in turn is a potent inhibitor of IGF bioactivity. Accordingly, low levels of PAPP-A in early pregnancy are linked with an increased risk for FGR, although the predictive value of this biomarker still remains poor (15). A recent study has investigated whether administration of IGF1 into the amniotic fluid can improve postnatal growth and metabolism in a sheep model of FGR, and results from this study look promising (16) (see Interventions for Improved Outcomes section). Glucocorticoid hormones play a central role in the development and maturation of fetal organs, while growth hormone, which is the major hormonal regulator of postnatal growth, has no demonstrable effect on fetal growth per se (17). Exogenous glucocorticoids are administered to pregnant women at imminent risk of preterm birth to mature the fetal lungs, and preterm birth is a common complication of FGR. Preclinical and clinical evidence demonstrates that antenatal steroids may exacerbate growth restriction (particularly repeat doses) (18) and that the FGR fetus differentially responds to antenatal steroids compared to appropriately-grown fetuses, likely mediated via altered placental response to steroids (19). Antenatal glucocorticoids may not significantly improve neonatal outcomes in FGR preterm infants (20), and indeed, may have adverse effects on brain development $(21,22)$. Further research is clearly needed in this area.

The fetus mounts a critical hemodynamic response to hypoxia, aimed at ensuring the most important fetal organs maximize their oxygen supply. This adaptive response redistributes blood flow away from peripheral vascular beds which is preferentially shunted toward essential organs, termed brain sparing (23). This results in preferential supply of blood flow to favor the brain, heart, and adrenals, at the expense of the gut, kidney, hematologic organs, and peripheral vascular beds. When fetal hypoxia is chronic in nature, as occurs with placental insufficiency, the persistent fetal hemodynamic shift has significant consequences for the fetus and neonate. Characteristically, prolonged fetal hypoxia reduces fetal weight overall, but also does so in an asymmetric manner, with relatively spared head size and a thin and/or shorter body length. While hemodynamic redistribution may be an attempt to protect vital organs from hypoxic injury, an adverse impact on fetal organ development and vascular remodeling is increasingly being recognized $(23,24)$. For example, the shunting of blood flow away from the kidneys is now recognized as contributing to suboptimal renal development with reduced nephron endowment (25). Further, sustained vasoconstriction of peripheral vascular beds alters local arterial wall properties including endothelial vasodilator dysfunction and sympathetic hyperinnervation, and consequently contributes to cardiac remodeling (26). The short and long-term consequences of sustained redistribution of cardiac output are profound, for 
both spared and non-spared organs, and these will be discussed in more detail below.

The overall incidence of FGR depends on the diagnostic criteria used, and the population being examined. It is estimated that between 3 and $9 \%$ of pregnancies in the developed world, and up to $25 \%$ of pregnancies in lowmiddle income countries are affected by $\operatorname{FGR}(27,28)$. Factors that influence FGR rates in communities include maternal nutrition, maternal and paternal smoking rates, alcohol and drug addiction, socio-economic status, maternal activity, stress during pregnancy and genetic make-up (29). The incidence of FGR is significantly higher in low- and middle- income countries, compared to high-income countries, and this is notably contributed by a large number of FGR infants born in the Asian continent, which accounts for approximately $75 \%$ of all affected infants in the world, followed by Africa and South America (30).

\section{CLASSIFICATION TYPES OF FGR}

FGR can be classified as early- or late-onset, reflecting the gestational age when growth restriction is diagnosed. Early onset FGR ( $<32$ weeks gestation) is the more severe phenotype, associated with significant disruption to placental perfusion leading to chronic fetal hypoxia, and with subsequent fetal cardiovascular adaptation in utero (31). Fetuses with early-onset placental insufficiency are more likely to be born preterm, to deteriorate over weeks, and have a high risk of morbidity or mortality. Late onset FGR ( $\geq 32$ weeks gestation) is the more common presentation of growth restriction (up to $80 \%$ of FGR cases), and is generally linked with a milder placental deficit, together with a lesser degree of fetal hemodynamic adaptation. Although placental dysfunction is mild, this group has a high risk of deteriorating rapidly, such that they have an elevated risk of stillbirth (31). This broad distinction between early- and late-onset FGR demonstrates that the timing when placental function becomes rate limiting for the fetus is a principal factor affecting outcome.

Advances in obstetric monitoring mean that it is increasingly likely that placental insufficiency and fetal growth restriction are detected during pregnancy. However, a significant proportion (up to 50\%) of FGR fetuses remain undiagnosed, and are first recognized only very late in pregnancy or at birth (3234). Furthermore, debate continues around the utility of third trimester ultrasound for the detection of late-onset FGR (35), with a recent study reporting that undiagnosed FGR does not lead to increased incidence of morbidity in neonates (36). These data likely reflect that it is predominantly the early-onset FGR infants with severe placental insufficiency, and worse neonatal outcomes, who are more straightforward to detect during pregnancy. Currently, no effective antenatal therapy exists for FGR, hence, delivery of the fetus remains the only viable option for a severely affected pregnancy; this often occurs preterm, introducing further risk of morbidity and mortality $(37,38)$. Together these data are indicative that the timing of the onset of placental insufficiency (early vs. late), gestation at birth, and

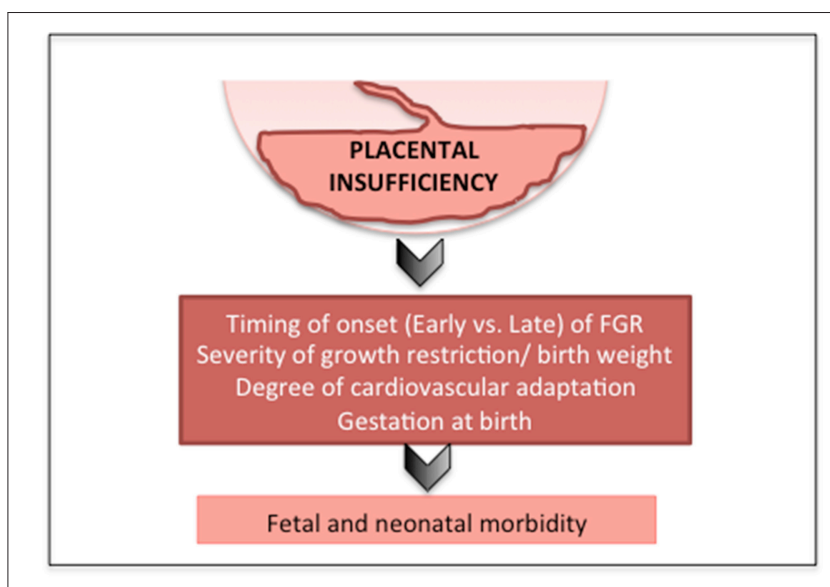

FIGURE 1 | Factors that affect outcomes in FGR.

severity of compromise/birth weight are the most predictive factors for neonatal outcomes (39) (Figure 1).

\section{PERINATAL MORBIDITIES}

A typical FGR infant at term age and an appropriately grown infant at term are shown in Figure 2. Key pathophysiological mechanisms driving fetal growth restriction and the resulting inutero and postnatal consequences are highlighted in Figure 3. Placental pathology and FGR are strongly associated with fetal demise in utero, and stillbirth (40-42). FGR is the greatest risk factor for stillbirth; overall it is shown that up to $50 \%$ of infants who are stillborn were small for gestational age or growth restricted (43). The detection, early diagnosis, surveillance and delivery of the severely growth restricted fetus are paramount to decrease stillbirth, but it remains that $40 \%$ of severe FGR infants ( $<3$ rd centile for birth weight) remain undetected in utero (44).

After birth, FGR infants are more likely to spend a significantly longer time in NICU compared to gestation age-matched infants (45). Accordingly, financial costs associated with the care of FGR infants are high, given that many of them will remain in NICU for prolonged periods $(46,47)$. FGR infants demonstrate elevated rates of intolerance to feeds/ milk, feeding difficulties and necrotizing enterocolitis (NEC). NEC is predominantly seen in infants who are born preterm, but late preterm infants are more likely to develop NEC if they were growth restricted (48). It is likely that in utero chronic fetal hypoxia and subsequent cardiovascular redistribution of blood flow away from the gastrointestinal tract contribute to immature gut development (49). FGR newborns, especially with abnormal flows in the umbilical artery prior to birth, are shown to have more feed intolerance when compared to their well-grown preterm counterparts (50). Superior mesenteric artery blood flows have been used as a marker for splanchnic perfusion in neonates and decreased flows correlate with feed intolerance (51). Application of near infra-red spectroscopy in the neonatal period as an assessment tool for monitoring gut perfusion can detect changes in splanchnic oxygen delivery, which may be reduced in FGR 


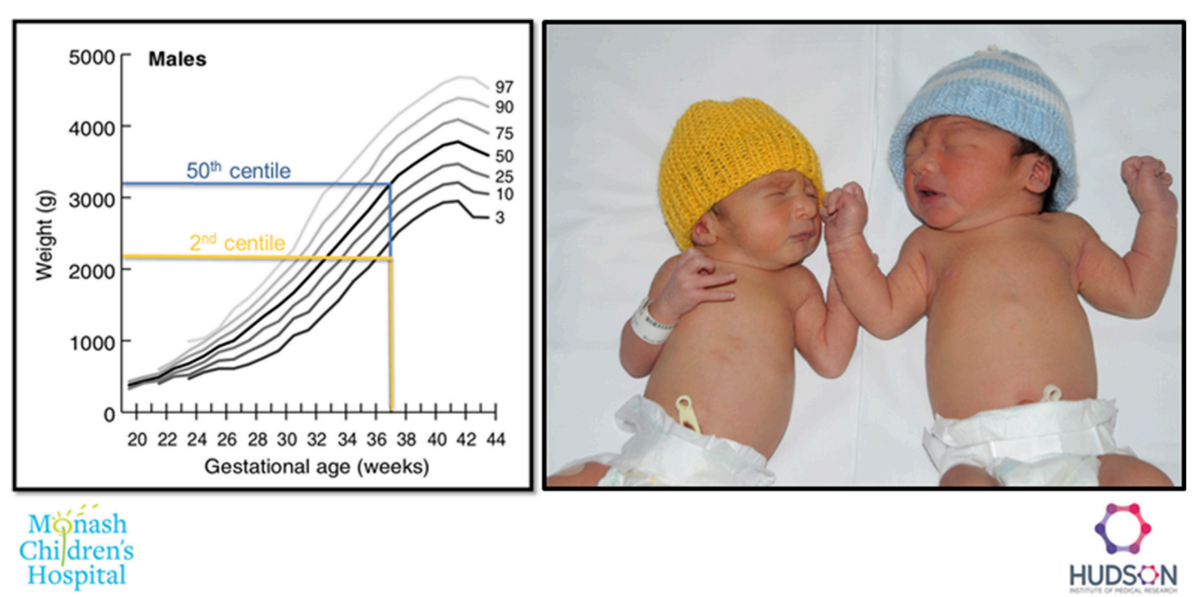

FIGURE 2 | Example of a FGR (2nd centile weight for age, yellow), and an appropriately grown (50th centile weight for age, blue) infant born at 37 weeks gestation.

infants and may predict feeding intolerance and development of NEC (52). Studies have shown that preterm FGR infants do not tolerate enteral feeds in the first few days of life (53) but conversely there is evidence that delaying enteral feeds in preterm FGR infants does not confer any protection against feed intolerance or NEC (54). In fact, it may delay establishment of feeds and increase length of stay in the neonatal unit (55).

Malnutrition and low birth weight puts FGR infants at an increased risk of a number of transient neonatal morbidities including hypothermia, altered glucose metabolism (hypoglycemia, hyperglycemia), hypocalcemia, polycythemia, jaundice and sepsis (5). Increased risk of infection is also common, potentially related to depressed immunological state and competence (56). FGR infants born preterm also have an increased risk of retinopathy of prematurity (57). FGR is linked to altered nephrogenesis, due to suboptimal tubular development caused by intrauterine hypoxia (58), and in turn, urinary Cystatin-C excretion is increased in FGR infants compared to appropriately-grown infants which is seen to reflect reduced renal volume (59). It is therefore suggested that increased secretion of Cystatin-C signifies nephron loss as a result of the negative impact of FGR on kidney development. Factors involved in nephron loss may include intrauterine hypoxia, decreased antioxidant capacity, and altered levels of growth factors.

\section{SPECIFIC NEONATAL MORBIDITIES (TABLE 1)}

\section{Cardiovascular Morbidity Clinical Features}

In addition to chronic hypoxia, placental insufficiency imposes other important stressors for the developing fetus, such as oxidative stress, inflammation and increased hemodynamic stress. This leads to elevated cardiac afterload due to high placental vascular resistance, which in turn directly and indirectly impacts on the developing cardiovascular system. It is now accepted that the fetal adaptations to these combined stressors sets the fetus, and future offspring, on a path of predetermined increased risk of cardiovascular disease $(60,61)$. It is also now apparent that subclinical or subtle evidence of cardiovascular dysfunction is present in fetal and/or early neonatal life, well before the onset of significant cardiovascular or metabolic disease in adulthood, supporting the notion of perinatal programming (60).

Advances in Doppler ultrasonography of the placental and fetal circulations provide a window of opportunity to observe and quantify fetal cardiovascular function, and early dysfunction. In early-onset FGR, severe placental insufficiency is characterized by high vascular resistance within placental vascular beds, resulting in absent or reversed diastolic umbilical artery flow, as well as high pulsatility index in the ductus venosus and increased dilation of cerebral vessels evident of fetal brain sparing (31). In late-onset FGR, umbilical artery flow may be normal, representing a milder placental insufficiency. Despite this, brain sparing is still evident, with increased cerebral to placental blood flow driven primarily by vasodilation within the middle cerebral artery in response to hypoxia (62). In both early- and late-onset FGR, increasing vasodilation within cerebral vascular beds is indicative of a worsening fetal state (63). Increased myocardial performance index, an index incorporating both diastolic and systolic function to assess global cardiac function/dysfunction, is evident from 24 weeks gestation in early onset-FGR fetuses (64). An increase in myocardial performance index is not indicative of improved performance, but rather demonstrates an increased time of systolic relaxation evident in early-onset FGR. Increased myocardial dysfunction is also present in lateonset FGR from $>35$ weeks gestation. In this population, lateonset placental insufficiency and FGR results in fetuses with larger, more globular hearts and early indices of functional deficits with impaired relaxation (65). This study is the first to show that late-onset placental insufficiency and FGR induces cardiac dysfunction that is detectable in the third trimester of pregnancy ( $\sim 35$ weeks gestation), indicating the presence of cardiac programming prior to birth. It has also been shown that 

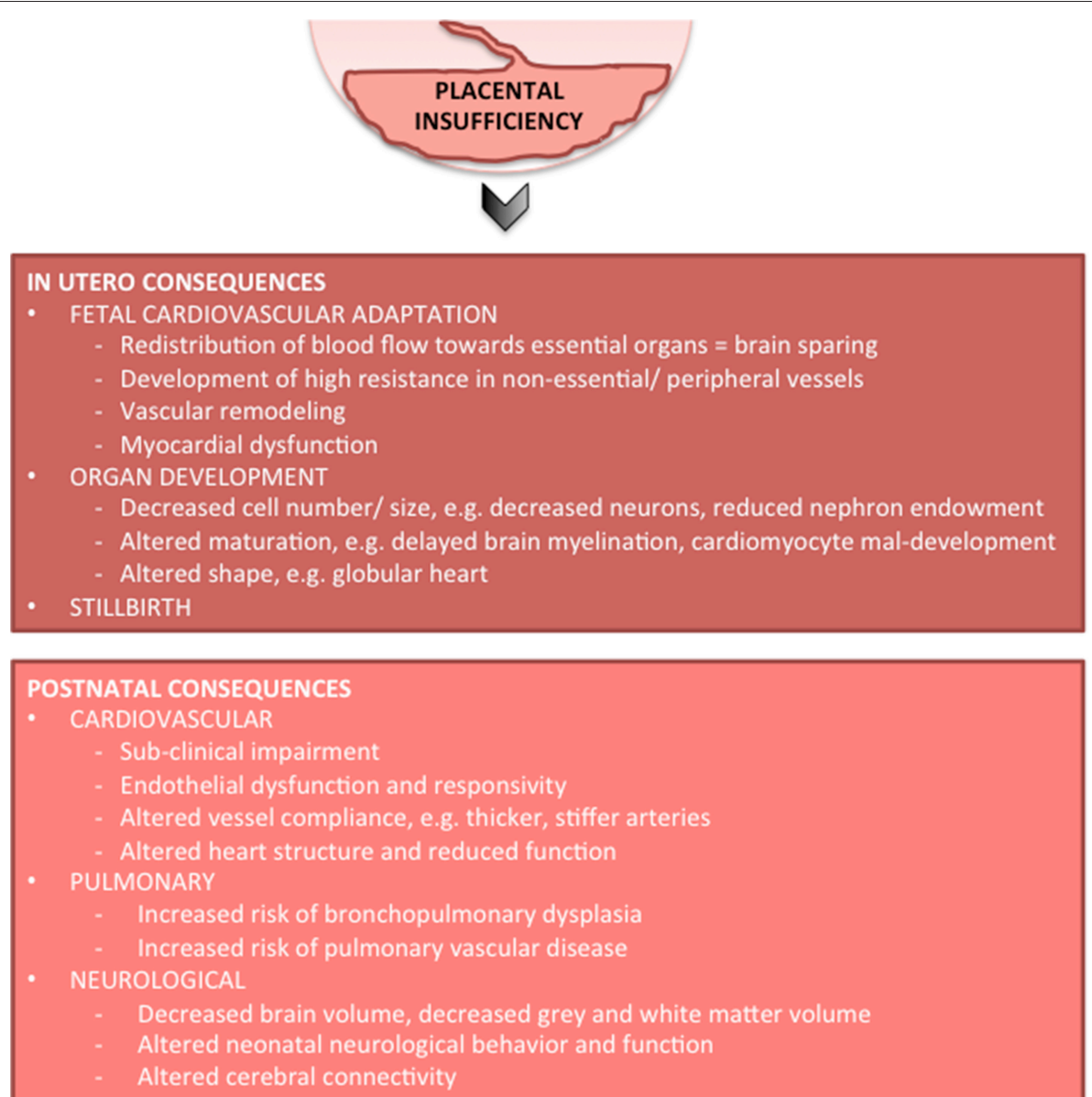

FIGURE 3 | In-utero and postnatal consequences of FGR and potential targeted therapies.

cardiac dysfunction and markers of cardiac injury such as BNP and H-FABP become increasingly worse as the severity of fetal compromise progresses (66).

\section{Pathophysiology}

In the presence of very high placental resistance associated with a sub-optimal pregnancy, the fetal heart contracts against an increased afterload, thereby increasing the work required to contract with each beat, resulting in increased heart wall stress and hypertrophy (65). Over a sustained period, hypertrophy increases wall thickness altering ventricular compliance. Increased afterload is evidenced by the presence of increased serum B-natriuretic peptide in infants born growth restricted (67).

Where placental insufficiency is present, the fetal heart must also adapt to a reduced supply of glucose, with the fetal heart producing ATP from glycolysis and oxidation of lactate. Despite this, cardiac glucose consumption is not altered in growth restriction due to increase in insulin receptor GLUT4 in the heart, which increases insulin transport to maintain glucose consumption (68). Thus, glucose availability is not considered a primary limiting factor for fetal cardiac function. More in-depth analysis of the effects of suboptimal oxygen and glucose supply to the developing heart can be examined 
TABLE 1 | Neonatal morbidities in fetal growth restriction.

\begin{tabular}{|c|c|c|c|c|}
\hline & Cardiovascular morbidity & Respiratory morbidity & Neurological morbidity & Others \\
\hline Neonatal period & $\begin{array}{l}\text { Early hypotension } \\
\text { Persistent fetal } \\
\text { circulation/PPHN } \\
\text { Structural heart changes } \\
\text { Vessel wall rigidity } \\
\text { Cardiac function issues } \\
\text { Late systemic hypertension } \\
\text { Secondary pulmonary } \\
\text { hypertension }\end{array}$ & $\begin{array}{l}\text { Increased need for } \\
\text { respiratory/ventilator } \\
\text { support } \\
\text { Meconium aspiration } \\
\text { syndrome } \\
\text { Pulmonary hemorrhage } \\
\text { Bronchopulmonary } \\
\text { dysplasia }\end{array}$ & $\begin{array}{l}\text { Perinatal asphyxia } \\
\text { Microcephaly } \\
\text { Cranial ultrasound abnormalities } \\
\text { (IVH, PVL) } \\
\text { White matter and gray matter } \\
\text { changes on MRI } \\
\text { Functional and DTI MRI changes } \\
\text { General movement assessment } \\
\text { abnormalities } \\
\text { EEG abnormalities }\end{array}$ & $\begin{array}{l}\text { Poor transition } \\
\text { Hypoglycemia } \\
\text { Hypocalcemia } \\
\text { Hypothermia } \\
\text { Sepsis } \\
\text { Jaundice } \\
\text { Polycythemia } \\
\text { Prolonged NICU stay } \\
\text { Feed intolerance } \\
\text { Delay in establishment of feeds } \\
\text { Necrotizing enterocolitis } \\
\text { Renal tubular injury } \\
\text { Retinopathy of prematurity }\end{array}$ \\
\hline Long term impact & $\begin{array}{l}\text { Hypertension } \\
\text { Ischemic heart disease } \\
\text { Stroke } \\
\text { Atherosclerosis }\end{array}$ & $\begin{array}{l}\text { Chronic respiratory } \\
\text { insufficiency } \\
\text { Reactive airway disease }\end{array}$ & $\begin{array}{l}\text { Neurodevelopmental issues } \\
\text { Behavioral problems } \\
\text { Learning difficulties } \\
\text { Cerebral palsy } \\
\text { Dementia } \\
\text { Mental health issues }\end{array}$ & $\begin{array}{l}\text { Failure to thrive } \\
\text { Obesity } \\
\text { Immune dysfunction } \\
\text { Osteoporosis } \\
\text { Metabolic syndrome } \\
\text { Renal issues } \\
\text { Hormonal issues } \\
\text { Cancer } \\
\text { Shortened life span }\end{array}$ \\
\hline
\end{tabular}

PPHN, persistent pulmonary hypertension; IVH, intraventricular hemorrhage; PVL, periventricular leukomalacia; MRI, magnetic resonance imaging; DTI, diffusion tensor imaging; EEG, electroencephalography; NICU, neonatal intensive care unit.

in animal studies of FGR (69). These studies show that the fetal heart is remodeled in a manner similar to that seen in dilated cardiomyopathy. Cardiomyocyte development is adversely affected and programmed cell death is increased in growth restricted fetal guinea pigs and sheep, with a persistence of the mononucleated, primitive cell type $(70,71)$. Permanent alterations in heart morphology are detected into adulthood, as evidenced by persistence in the deficits in cardiomyocyte number and cardiac hypertrophy (70).

The transition to ex utero represents a particularly critical period where the heart must rapidly adapt to new pressure and flow demands. After birth, the external pressures around the heart are reduced, due to alleviation of the liquid-filled lungs and amniotic fluid. Concurrently, the low resistance placental circulation is removed, temporarily decreasing cardiac output and increasing afterload, and thus heart rate, enddiastolic pressure and stroke volume must all be increased to maintain adequate cardiac output. In response to these altered pressure demands throughout the transition to exutero life, the myocardium undergoes rapid changes in cardiac muscle protein expression (72). One critical change precipitated by such pressure changes at birth is a shift in the fibrous component of sarcomeres toward smaller isoforms, which increase the passive tension within with postnatal heart (72). It is postulated that the growth-restricted fetus undergoes these changes in utero, due to the presence of increased afterload secondary to high placental resistance, and resulting in altered cardiac compliance (73). In human infants and in experimental animal models of FGR, the heart is shown to have shorter sarcomeres, which likely contributes to decreased contractile strength $(73,74)$. Further, changes in the large sarcomere protein titin are described in the FGR heart, reflecting a shift from a large compliant isoform toward a small and stiff isoform (73). As titin is a major determinant of sarcomere length, this change in isoform is consistent with overall reduction in sarcomere length in the hearts of growthrestricted fetuses, and has consequences for cardiac development and function.

Changes in the hearts of growth-restricted fetuses are directly coupled with changes in the wider cardiovascular system, notably the vasculature. It is now well described that vascular responses to placental insufficiency and chronic hypoxia are vascular bed-dependent. In peripheral vascular beds, human and animal data show that sustained vasoconstriction and peripheral vascular resistance in response to chronic hypoxia induces arterial stiffness and elevated central pulse pressure (7577). Growth restriction induced via chronic hypoxia increases peripheral vascular tone via numerous methods, including endothelial dysfunction (76), increased sympathetic nervous system activation (69) and oxidative stress (78). Oxidative stress, induced via increased reactive oxygen species generation, quenches nitric oxide (NO), thereby reducing its bioavailability and increasing peripheral vascular tone. We have previously described an increase in plasma urate levels arising from chronic fetal hypoxia (78) suggesting activation of a potent oxidative enzyme, xanthine oxidase. Importantly, it is this altered vascular tone in fetal life that sets up developmental programming for future hypertension, as evidenced in both FGR animals (79) and human cohorts (61). Central vessels, such as the aorta and carotid arteries, have increased wall thickness (80) and increased stiffness (81) in FGR humans and animals. The vascular changes described above persist into adulthood, however, they are more 
pronounced in peripheral vascular beds compared to central vascular bed (82).

Vascular compensation is observed in FGR offspring, wherein remodeling of the arterial wall, collagen and elastin content contribute to altered vascular mechanics (83). Rodent and guinea pig studies show that interruption of fetal growth in mid gestation coincides with a crucial period of elastin production within vasculature, attenuating elastin deposition and subsequently content, such that elastin is reduced and collagen increased $(84,85)$. This remodeling greatly impacts on vascular mechanics, as collagen is 100-times stiffer than elastin and, as a consequence, vascular stiffness is significantly increased (85). These changes in vessel biomechanics are most notably in the lower body arteries of growth-restricted offspring (83). Following low protein diet restriction, the aorta from adolescent rodents are not only stiffer, they also have increased fibrotic tendency, despite being normotensive (67). However, a more profound effect on vascular extracellular matrix remodeling is seen with placental dysfunction-induced growth restriction, compared to other factors such as diet (high fat) or fetal sex. These data are suggestive that vascular remodeling occurs primarily in response to changes in pressure and flow caused by chronic hypoxia and adaptive hemodynamic redistribution, rather than metabolic or hormone alterations.

\section{Impact}

The evidence presented above all indicates that exposure to placental insufficiency and chronic hypoxia significantly alters fetal development of the cardiovascular system. Unsurprisingly, the fetal cardiovascular alterations subsequent to placental insufficiency persist into clearly detectable structural and functional changes in the early postnatal period. After birth, tissue Doppler imaging (TDI) has allowed detection of persistent sub-clinical changes in movement and timing of the myocardium throughout the cardiac cycle, in particular during myocardial relaxation (86). In the first days of life, infants who were growth restricted show altered cardiac structure detectable on ultrasound with decreased sphericity index (a more globular shape), together with increased interventricular septum and left ventricle wall thickness (77). Further, load-dependent diastolic function is impaired $(77,87)$ this often represents impaired cardiac relaxation resulting in the transition from contraction to relaxation occurring prior to aortic valve opening, a situation which is common in hearts exposed to chronically high afterload. Frequently, FGR does not alter overall cardiac output, however components of cardiac output are altered with decreased stroke volume and increased heart rate often presenting in the FGR newborn (86). With increasing severity of FGR there is increased biomarkers of myocardiac cell damage, such as heart fatty acid binding protein (H-FABP), and incremental worsening of both systolic and diastolic dysfunction and in particular heart relaxation is altered (66). These alterations are indicative of hemodynamic compromise and are linked to worsening outcomes including fetal demise (88). Early signs of alteration in blood pressure in association with FGR remains contentious-we have documented increased blood pressure in the early postnatal period (80), whilst others show no change in blood pressure
(82); these differences may reflect the difference between clinical and pre-clinical studies or the severity of the growth restriction induced.

In turn, in utero cardiac and vascular remodeling in FGR neonates programs for cardiovascular disease into adulthood. Indeed, the consequences of growth restriction on adult cardiovascular function are now well studied, and are central to the Developmental Origins of Health and Disease (DOHAD) hypothesis. These findings are apparent from both human epidemiological and experimental paradigms in growthrestricted offspring $(76,85)$ and adults $(60)$. Long-term evidence of the link between low birth weight and developmental programming is available in the infants born in famine conditions in Europe in the 1900s wherein SGA is linked with significantly higher blood pressure in later life (89), and with increased risk of ischemic heart disease and cerebrovascular disease (90). Precursors of long-term suboptimal outcomes such as stroke and hypertension (91) have been proposed to be evident in growth restriction offspring as pre-atherosclerotic vascular damage in both newborns (92) and 18 month old FGR offspring (93).

Despite excellent evidence of the link between FGR and adult cardiovascular disease, there is some difficulty in dissociating the potentially separate effects of placental insufficiency/FGR and preterm birth. Growth restricted fetuses are often born preterm, particularly early-onset severe FGR infants, and preterm birth is also associated with adverse effects on the developing cardiovascular system (94). A recent study by Cohen et al. (87) followed both preterm and preterm FGR infants to 6 months of age to determine cardiac morphology. They found that changes in cardiac structure and function associated with preterm birth alone were sub-clinical, and normalized in childhood, while only thickened ventricular walls persisted into 6 months of age in FGR infants (87). This study goes some way to delineate the separate effects of prematurity and growth restriction and suggests a possible persistence of structural changes in FGR over and above the effects of prematurity.

\section{Respiratory Morbidity Clinical Features}

There is heterogeneity in descriptions of pulmonary complications associated with FGR, which probably reflect the heterogeneity in growth restriction itself. There is however good evidence that chronic hypoxia associated with FGR interrupts normal pulmonary development, and increases susceptibility to both short- and long-term respiratory compromise. Preterm FGR newborns are $45 \%$ more likely to have bronchopulmonary dysplasia (BPD) or die from respiratory complications after birth as compared to well-grown infants (45). Further, even FGR infants born at term have worse respiratory outcomes than appropriately grown infants (95). FGR infants spend a significantly increased time in NICU and on mechanical ventilation compared to age-matched control infants, and rates of respiratory distress syndrome (70) and BPD are increased with FGR $(45,96,97)$. Indeed, large multicenter trials for early-onset FGR describe that BPD is the most common morbidity for this population. The risk of BPD is greater when FGR and preterm 
birth are co-morbidities. Growth restriction is also associated with pulmonary hypertension of the newborn (96). FGR is associated with impaired lung function in children (98) that can persist to adulthood (99).

\section{Pathophysiology}

Human FGR cohort studies and preclinical animal studies describe that FGR can result in altered lung development; in some cases these are subtle structural and/or biochemical changes, wherein the timing and severity of compromise modulates effect. In animal studies, an early onset placental or hypoxic compromise mediates a more pronounced adverse outcome. Chronic hypoxia in fetal sheep resulting in FGR induces an adaptive response within the developing lung, where genes regulating hypoxic signaling, lung liquid reabsorption and surfactant maturation are increased (100). A 2-week exposure to hypoxia alone in rats disrupts alveolarization, reducing alveolar number via reduced septation (101). In fetal sheep we have induced late-onset placental insufficiency and FGR to examine lung morphology in preterm and term-born lambs. Lambs born naturally at term have simplified lung architecture with decreased secondary crest abundance and increased elastin deposition (102). Lambs that are delivered preterm and exposed to $2 \mathrm{~h}$ of mechanical ventilation do not demonstrate a difference in lung structure between FGR and appropriately-grown lambs, with no difference in the ratio of lung tissue to airspace or septal crest density, however the early tissue injury marker cyr61 is significantly increased in FGR lambs (103). Further, we observed that both FGR and appropriately grown lambs had similar ventilation requirements in the first hours of life. These findings extend previous results in FGR animal experiments from our group (104) and others $(105,106)$, which find no overt difference in pulmonary structure of FGR offspring. When we compare results between our preterm and term lamb cohorts, it is evident that the timing and duration of placental insufficiency is a critical determinant of lung dysfunction. We have recently examined the effects of early-onset placental insufficiency on lung structure and function, finding that lung cellular morphological changes are present (unpublished results). Accordingly, we propose that altered lung structural development is dependent on the timing of compromise, rather than the severity of growth restriction. Further, in early-onset FGR, the severity of fetal hypoxia has an inverse relationship with pulmonary surfactant production leading to decreased surfactant, a relationship not maintained in late-onset FGR (107). It is well accepted that without adequate surfactant, the newborn is at increased risk of pulmonary complications after birth, particularly when the infant is born preterm.

As discussed above, chronic hypoxia results in the fetal adaptive response of redistribution of cardiac output. MRI studies have confirmed that in late gestation of human fetuses, growth restriction is associated with an increased superior vena cava flow and, consequently, decreased pulmonary artery flow (108). This hemodynamic response is contributed by increased pulmonary vascular resistance (97). Increased pulmonary vascular resistance also reduces venous return to the left heart (109) and enhances right ventricular afterload. Combined ventricular output is thus maintained (108). Postnatally, FGR does not alter pulmonary blood flow during the transition to ex utero life, but left ventricular output is lower (110). Thus it is apparent that the hemodynamic adaptation to chronic hypoxia also has important implications for pulmonary vascular development, and accordingly, lung structure and function in FGR offspring.

A handful of studies have also examined fetal breathing movements in the developing fetus, and undertaken comparison in FGR versus appropriately grown fetuses. Fetal breathing movements are an important component of normal lung development, as they provide a stretch stimulus for growth throughout gestation (111). In FGR sheep, fetal breathing movements are significantly reduced in late gestation, although it is noted that not all experimental models of placental insufficiency show such changes (69). The cessation of fetal breathing movements in response to placental insufficiency is thought to occur by way of physiological response to reduce metabolic rate and thus conservation of oxygen, and is associated with disrupted alveolarization (112).

Deficits in pulmonary development subsequent to placental compromise are not confined to lung alveolar morphology. There is a growing understanding of the link between poor alveolar development and poor lung vascular development (113-115), called the Vascular Hypothesis. Growth restriction, induced via hyperthermia in pregnant sheep, impairs both lung alveolar and vascular development in the developing fetus (116). In complimentary experiments, lung alveolar cells isolated from the same growth-restricted fetuses demonstrate reduced cell growth, migration and branching, which are key components of normal lung development (116). These findings are confirmed in vivo in which growth-restricted offspring demonstrate diminished pulmonary vascular function and density, together with decreased pulmonary alveolarization $(116,117)$. Abnormal pulmonary vascular development in growth restricted fetuses is likely to be a key mechanism increasing the risk of BPD, pulmonary hypertension and life-long reduction in respiratory capacity, such as seen in chronic obstructive disease (116).

\section{Impact}

BPD is a chronic lung disease characterized by arrested airway and parenchymal development and resulting in longterm respiratory complications, with a high susceptibility in preterm and growth restricted infants. BPD is a multifactorial condition, however it is primarily thought to result from chronic ventilation-induced injury in preterm infants, contributed by lung exposure to excess oxygen and inflammation. FGR is an independent risk factor for BPD in human infants (118-120). Being born subsequent to placental insufficiency and growth restricted is associated with a 3.6-fold higher risk of developing BPD than age-matched control infants (120), despite FGR infants having similar RDS rates as appropriately-grown counterparts. Lio et al. (121) have also recently shown that FGR infants with placental dysfunction have a 6-fold increased risk of developing BPD compared to low birth weight/ SGA infants. Further, they noted that birth weight per se and not ventilation duration, or other neonatal morbidities, contributed to the presence of BPD. 
Maternal vascular unit deficiency, a marker for pre-eclampsia, is a common placental pathology associated with FGR, and it has also been shown that maternal vascular unit dysfunction doubles the risk of BPD in preterm human infants (118). Thus, human and animal data strongly support that the foundations of postnatal lung deficits and BPD are laid down in utero in FGR infants with placental insufficiency, and that vascular pathology is likely to be a contributing factor.

Neonatal pulmonary hypertension is highly associated with decreasing gestational age and low birth weight, and is a common complication of BPD (96). Pulmonary hypertension is characterized by hypoxemia of the newborn and right-to left shunting through the ductus arteriosus, due to maintenance of high pressures within the pulmonary circulation. Accordingly, neonatal pulmonary hypertension occurs via a failure of structural cardiovascular remodeling after birth, and is likely developmentally programmed in utero (122). In post mortem tissue analysis it is shown that newborns with pulmonary hypertension displayed reduced pulmonary vascular surface area with increased muscularization of distal pulmonary vasculature (123). These data suggest a strong association with FGR induced by vascular remodeling in chronically hypoxic fetuses, resulting in impaired control of vascular tone within the pulmonary circulation after birth. Altered pulmonary vascular composition has been more closely examined in growth restricted rats, demonstrating increased pulmonary vasoconstriction caused by local endothelial dysfunction and excessive collagen and reduced elastin in the pulmonary vasculature (124). Animal models of FGR also provide strong evidence that the hallmarks of pulmonary hypertension are already present in the growthrestricted fetus and offspring soon after birth. Our group and others have shown vascular changes, including decreased vascular density and dysfunction in fetal sheep (116) and in 2h-old lambs (110). Thus, even prior to birth, FGR is associated with pulmonary hypertension.

The long-term effects of low birth weight have been examined in adult offspring conceived during the 1940s Dutch famine, who show an increased risk of obstructive airway disease (89). Further analysis of this cohort determined that neither serum immunoglobulin E concentration nor mean lung volumes were different (125). The authors speculate that bronchial reactivity must be the cause of the airway disease following growth restriction.

\section{Neurological Morbidity \\ Clinical Features}

FGR is strongly linked to suboptimal brain development, and long-term neurological dysfunctions in motor ability, cognition and learning, and behavior. We have recently reviewed the consequences of placental insufficiency and FGR on the developing brain (28), and describe that the age of onset and severity of FGR, together with gestational age at birth, play important modulatory roles in altered brain structure and function. The first indication of structural anomalies of the FGR brain can be derived from magnetic resonance imaging (MRI) during fetal development. MRI of the fetal brain during development demonstrates reduced brain volume, and altered cortical folding and brain morphology in FGR fetuses $(126,127)$. Arthurs et al. (128) showed lower diffusion weighted imaging values in parts of the brain in severe FGR fetuses as compared to normal age-matched controls, which were suggestive of an abnormal maturational profile. Postnatally, at term-equivalent age, MRI detects reduced intracranial volume, particularly contributed by decreased cortical gray matter volume in FGR infants (129), and altered developmental profile of white matter myelination (130), the hippocampus (131) and the basal ganglia (132) of growth-restricted infants, compared to appropriately grown infants. Functional MRI is also an upcoming tool to study whole brain functional networks in newborn infants for the assessment of altered organization and prediction of longterm neurodevelopment (133). Diffusion tensor imaging (DTI) and connectivity-based analysis of the FGR brain in the neonatal period is also being increasingly investigated (134).

MRI has the ability to detect even relatively small volume, structural, and organizational differences within the brain of FGR and appropriately-grown infants (135) but MRI capability and expertise in analysis is not readily available at all birth centers. In contrast, neonatal cranial US is widely used, but shows less sensitivity for detection of these subtle, but important neurological changes associated with neuropathology in FGR infants (136). Cranial ultrasound is frequently used as an assessment tool in premature infants, and term infants with severe FGR, to identify significant neuropathology in the neonatal period. There remains uncertainty as to whether cranial ultrasound can adequately detect neuropathology associated with FGR when compared to age-matched appropriately grown preterm infants $(135,136)$. Certainly in older preterm and term FGR infants, the benefit of routine cranial ultrasound screening in the neonatal period is questionable (137). We did not find evidence of altered cerebral ventricular volume using ultrasound imaging in FGR infants < 10th centile, however we did observe a correlation between increasing ventricular volume and a decrease in functional motor scores (138). Cruz-Martinez et al. (139) have suggested that FGR infants with signs of middle cerebral artery and other Doppler abnormalities (indicative of significant brain sparing) are more likely to have neuropathology that can be detected on neonatal cranial ultrasound. This is interesting, as it further supports that the term brain sparing is a misnomer, and while it represents an appropriate survival response in the fetus, it is actually associated with worsening fetal condition and greater brain injury (28).

FGR infants frequently have a reduced head circumference compared to age-matched appropriately-grown infants, which is likely due to reduced brain volume (129), and reduced brain volume persists to 12 months of age (140). Cerebellar and hippocampal volumes may also be reduced (130). Brain myelination and connectivity have been shown to be adversely affected in FGR infants in the first 12 months of life, representative of white matter injury (141). Diffusion MRI of the human brain shows that the overall neuronal network complexity and connectivity of the FGR brain is reduced, with reduced global and local axonal circuits (142). Long-range cortical-basal ganglia (thalamocortical) connections are decreased in children born preterm with FGR, compared to children born preterm 
but appropriately-grown (142), indicating that brain connectivity is significantly worse in children who were FGR compared to children who were preterm but well-grown. Deficits in brain connectivity correlate with neurobehavioral impairments including hyperactivity and poor cognition at school in children who were born FGR (143).

Neonatal functional assessment may detect early problems with neurological processing and behavior in infants who were born growth restricted. Tolsa et al. (129) showed that FGR newborns had specific alterations of brain structure as studied by volumetric MRI at preterm and term age, with reduced cortical gray matter volume correlating with deficits in attention and responsivity at term-equivalent age. General movement assessments (Prechtl movements) provide an early motor analysis, wherein abnormalities are predictive for cerebral palsy, and general movements may be adversely affected in some FGR infants (144). Similarly, electroencephalography performed early in the neonatal period has been shown to be affected and may correlate with adverse neurodevelopment in studies of FGR infants $(145,146)$. There is however limited data on early detection of functional deficits in growth-restricted infants, reflecting challenges in detecting delayed neurodevelopment in the neonatal period.

\section{Pathophysiology}

It is now well established that the traditional brain sparing physiology does not necessarily mean normal cerebral development in utero (28). In fact, fetuses with the most severe brain sparing are at the highest risk of adverse neurodevelopment in childhood. Prenatal loss of vasoreactivity in FGR has been suggested as a mechanism for poor outcomes, in which fetuses who do not adjust their cerebral circulatory control in response to hypoxic challenge may be more at risk of impaired cerebrovascular regulation (147). There are also reports of preferential perfusion and cerebral redistribution of brain blood flow in FGR fetuses, leading to some brain regions being at higher risk of injury (148). This is supported by work in fetal sheep to demonstrate that FGR is associated with regional cerebral blood flow redistribution, with the most notable differences between FGR and appropriately grown fetuses seen in the cerebral cortex and periventricular white matter (21).

Cerebral blood flow frequently continues to be abnormal for the first few days after birth in FGR human infants, but whether this puts infants at an increased risk of acute brain injury is not known. It has been reported the cerebral blood flow remains elevated after birth in FGR infants (149), even when the neonate is no longer exposed to a hypoxic environment and is no longer in need of a compensatory change in cardiac output. Postnatally, elevated cerebral blood flow might potentiate hyperoxia and oxidative stress within the fragile brain, which could also contribute to further neurological damage.

Animal models of chronic hypoxia and growth restriction have helped us to understand the development of neuropathology associated with placental insufficiency and FGR (28, 150-152). Adverse effects on brain gray matter development, white matter, and cerebellum have been described both in sheep, rabbit and rat models of FGR (153-155). In fetal sheep, we showed that earlyonset placental dysfunction is associated with more widespread and severe white matter brain injury and neuroinflammation compared with late-onset, however both early- and late-onset FGR demonstrate complex patterns of gray and white matter neuropathology (154). Animal studies also show that the severity of brain injury, and the resultant neurodevelopment deficits, depends on the extent and severity of brain involvement in FGR (156). Hypomyelination and delayed myelination due to oligodendrocyte maturational deficits have been identified as possible mechanisms causing the white matter injury seen in FGR infants (157). Deficits in neuronal connectivity have also been described in animal models (158). Our group, and others, has observed that deficits in various components of the neurovascular unit play a significant role in the brain injury seen in animal models of FGR (159). Prematurity is a confounder in human FGR, but studies in FGR animals allow the separation of growth restriction and preterm birth. The individual contributions of preterm birth and/or neonatal ventilation of the FGR newborn on the progression of brain injury are now being examined $(160,161)$. These studies have determined that preterm birth and ventilation synergistically predispose the vulnerable FGR brain to neuropathology.

\section{Impact}

FGR infants are at increased risk of adverse neurodevelopmental outcomes in childhood. Neurological morbidities related to motor deficits, including cerebral palsy, behavioral issues, and cognitive impairment is significantly increased in young children and adolescents who were diagnosed as growth restricted at birth $(28,162-164)$. The risk of cerebral palsy is 30 -fold greater in FGR infants, compared to those that are well grown (165), and increases with worsening growth restriction. Overall, $>40 \%$ of children who have cerebral palsy had a low birth weight; that is, they were growth restricted, born preterm, or both (166). This is important, as FGR and preterm birth are frequent co-morbidities. In addition to motor deficits, preterm FGR infants followed-up at 1, 2, and 3 years of age showed deficits in cognition and behavioral outcomes compared to preterm age-matched appropriately-grown infants (167). Further, a longitudinal study observing FGR offspring with evidence of brain sparing from birth to middle school age (9-10 years old) found a complex set of neurodevelopmental deficits, such as a significant reduction in IQ, compared to age-matched appropriately-grown children (168). Multiple follow-up studies of FGR infants into school age describe diminished gross and fine motor skills, cognition, memory, and academic ability, as well as neuropsychological dysfunctions encompassing poor attention, hyperactivity and altered mood $(143,169-171)$. FGR infants born preterm and those with fetal circulatory redistribution are at the greatest risk for the worst outcomes (172). These adverse outcomes can continue into adolescence and young adulthood (173). It is apparent that determining the neurodevelopmental consequences of FGR is complicated by the severity of FGR, early- or late-onset, and the gestational age at delivery (28). However, in both early- and late-onset FGR, the presence of 
cardiovascular redistribution and brain-sparing is associated with abnormal neurodevelopmental outcomes (28).

\section{Interventions for Improved Outcomes}

Management of pregnancies complicated by FGR represents a balance between antenatal compromise, often with worsening chronic hypoxia that contributes to subpotimal organ development, and the risks associated with preterm delivery and postnatal intensive care, which may also contribute to morbidities. In high-income countries, about half of fetuses with moderate- to severe-growth restriction are detected antenatally and are therefore amenable to treatment during pregnancy, but it remains that nearly $40 \%$ of infants born at the $3^{\text {rd }}$ centile for weight are not detected in utero (44). With this in mind, both antenatal and postnatal therapies must be considered. Currently, no specific treatment is available for FGR. Potential treatments should target maldevelopment of multiple organs, various injurious pathways, cell types, and structural deficits that manifest over different developmental stages. Here we will provide an overview of the current state of understanding for a handful of treatments for FGR (Figure 3).

\section{Antenatal}

Antenatal treatments are principally aimed at improving placental function and thereby increasing fetal growth in utero. To date, the best studied of these has been sildenafil citrate. Sildenafil is a potent phosphodiesterase type 5 (PDE5) inhibitor that is an effective smooth muscle relaxant where the PDE5 enzyme is present in an organ or tissue, as is the case for the human placenta (174). The effects of sildenafil on smooth muscle are mediated via an enhanced and prolonged nitric oxide release leading to vasodilatation. Both in vitro and in vivo studies demonstrate that sildenafil vasodilates human myometrium vessels from normal $(175,176)$ and growth restricted placenta. Most experimental studies to date support that sildenafil increases fetal weight in compromised rat, sheep and human pregnancies (177). In contrast, we have shown that antenatal sildenafil administration to pregnant sheep with placental insufficiency decreases fetal weight and worsens fetal hypoxia (178). Although initial preclinical evidence for the multinational STRIDER trial suggested improved outcomes for FGR infants, this trial has now been aborted due to unexpected baby deaths (179), leading to a call for increased preclinical studies underpinning clinical trials (180), and improved understanding of the effects of sildenafil on the fetus given that it crosses the placenta (181). The longer acting tadalafil remains an active clinical experimental treatment of interest as an antenatal therapy for FGR and, given that tadalafil does not cross placenta (174), it may be more favorable as a targeted placental treatment.

The EVERREST Project is also investigating a targeted approach to improve placental function in pregnancies complicated by FGR using gene therapy to inject vascular endothelial growth factor (VEGF) into uterine arteries (182). VEGF is known for its role in inducing angiogenesis and in the EVERREST Project it is hypothesized that application of adenovirus VEGF in, or near placental arteries will induce a local and acute increase in VEGF expression, and subsequent angiogenesis of the placental vasculature. Preclinical studies have shown promise with improved blood flow (183) and fetal weight gain (184) in animal models of growth restriction, resulting from the improved vascularization of the placenta. The clinical trial is ongoing.

A recent large animal (sheep) study examined intra-amniotic administration of the growth-promoting protein insulin-like growth factor-1 (IGF-1) (16). This work showed that increasing the bioavailability of IGF-1 in pregnancies complicated by placental insufficiency and FGR improved birth weight in female lambs, but not males, and modified postnatal catch-up growth in both females and males. Intrauterine IGF-1 also mediated expression of key somatotrophic and metabolic genes, indicative that antenatal treatment could be utilized to positively affect postnatal growth and wellbeing.

A number of antenatal treatments have been explored preclinically that aim to restore fetal oxidative tone via maternal antioxidant administration, using agents such as allopurinol, melatonin and vitamin C $(75,79,185)$. Antioxidant treatment has principally targeted improved cardiovascular and neurological outcomes in growth-restricted offspring. To date, melatonin has been the most widely studied, given melatonin's established safety profile, ease of administration, and strong antioxidant benefits. In sheep, we have shown that maternal melatonin administration to ewes carrying a growth restricted fetus results in a significant improvement in vascular function and reduced arterial stiffness, two vital pathologies evident in FGR offspring, which predispose to cardiovascular disease (75). Melatonin administration also resulted in improved cardiac function in the right ventricle. Further, this study showed that maternal melatonin improved fetal oxygenation and increased birth weight (75), however other ovine studies show either no improvement in birth weight (186) or exacerbation of growth restriction with melatonin (187). In cultured human umbilical vein endothelial cells (HUVECs), melatonin improves vascular endothelial integrity, likely via combined anti-oxidant and anti-inflammatory mechanisms (188). Exposure to antenatal melatonin does not reverse alveolar simplification in FGR newborn lambs (102), but does improve pulmonary vascular structure and function (189), and pulmonary tone may be maintained long term via alteration to receptor populations (190). As our understanding of perturbations to lung growth in FGR offspring continues to be explored, so too does the opportunity for targeting novel pathways. For example, recent work has shown that NPY is down regulated in FGR, where NPY is a sympathetic neurotransmitter that is critical for normal lung growth (191).

The effects of maternal melatonin administration on brain development have also been examined. Antenatal melatonin crosses the placental and the blood brain barrier, and melatonin is a strong antioxidant and also demonstrates anti-inflammatory benefits in the developing brain $(186,192-194)$. In pregnancies complicated by placental insufficiency and FGR, maternal melatonin improves white matter brain development via increased myelination and decreased axonopathy in the fetal brain, and subsequently, neurobehavior of FGR+MLT lambs is significantly improved after birth (186). Melatonin has also been shown to have beneficial effects on cerebral vasculature 
by preventing FGR-related apoptosis and disruption of blood brain barrier instability via improved vascular interactions with astrocytes and pericytes (195). Antenatal melatonin has been examined in pilot studies to treat FGR (186) and preeclampsia (188) with results supporting that melatonin is an effective antioxidant that is safe for the mother and baby, and may extend pregnancy (196).

Emerging evidence supports that the glycoprotein lactoferrin shows potential as an antenatal treatment for pregnancies complicated by FGR, particularly for the developing brain (197). Lactoferrin is a glycoprotein that demonstrates strong antioxidant, anti-inflammatory and anti-microbial effectsimportant factors that could mediate neuroprotective benefits. In rats, lactoferrin supplementation during pregnancy shows positive benefits for dexamethasone-induced fetal growth restriction (197). Maternal lactoferrin significantly increased birth weight of control rat pups, and FGR offspring exposed to lactoferrin showed a normalized weight at postnatal day 21 . Lactoferrin supplementation also improved brain hippocampal structure and stimulated brain derived neurotrophic factor (BDNF) (197), important observations in light of the neuropathology associated with human FGR. Nutritional supplementation (glucose, amino acids and electrolytes) into the amniotic sac of FGR rabbits has also recently been explored, with some promising results suggesting that survival rate for FGR offspring was improved with treatment, although birth weight and cardiac function deficits were not improved (198).

\section{Postnatal}

As mentioned above, nearly $40 \%$ of human infants with severe FGR are not detected antenatally (44), and therefore not amenable to antenatal treatments. In light of this we must continue to investigate therapies to improve multi-organ dysfunctions in growth restricted infants. We have highlighted in this paper that deficits in cardiovascular, pulmonary and cerebral development are already present at birth in FGR infants, principally caused by chronic hypoxia in utero. Therefore any potential postnatal therapy would aim to be reparative and to prevent progression of ongoing multi-organ damage.

Lactoferrin shows great potential as a postnatal therapy, in addition to positive effects antenatally. Lactoferrin is highly abundant in human colostrum and milk, and it reaches the brain after oral administration (197, 199). In this regard, breastfed infants show higher total anti-oxidant capacity and a lower oxidative stress index compared to non-breastfed infants. Importantly, randomized controlled trials with nutritional lactoferrin supplementation in premature neonates demonstrate a promising reduction in late onset sepsis and necrotizing enterocolitis (200). Lactoferrin supplementation during lactation is protective for neonatal rats exposed to either hypoxiaischemia or lipopolysaccharide-induced systemic inflammation $(201,202)$. Analysis of the neonatal rat brain using a combination of advanced MRI analysis and histology demonstrates that gray and white matter microstructure is normalized with lactoferrin supplementation, myelination is protected and measures of axonal integrity and brain organization are restored in rats with lactoferrin supplementation (201). Early environment enrichment or postnatal stimulation has also been shown to have some benefits in brain connectivity in a rabbit model of FGR (203). While there are no current published studies on stem cell therapy for FGR related brain injury, our lab and others are working on testing their applications in FGR and other pregnancy complications (204). The application of postnatal therapies to improve multi-organ deficits associated with FGR should remain a foremost preclinical research area.

\section{CONCLUSIONS}

Understanding the pathophysiological mechanisms that underlie neonatal morbidities that are particularly associated with FGR provide the fundamental basis for improving shortand long-term outcomes in growth restricted offspring. It is clear that placental compromise and chronic fetal hypoxia program the fetus for suboptimal growth and development, with fetal cardiovascular dysfunctions and altered organ development already apparent in the FGR fetus during pregnancy. The timing of the onset of placental insufficiency, the severity of growth restriction, the degree of cardiovascular adaptation, and gestational age at birth are all critical factors that modify outcome for FGR infants. In the neonatal period, FGR infants demonstrate early evidence of cardiac, vascular, pulmonary, neurological and other deficits, which can lead to long durations in neonatal intensive care, and long-term health problems. Improved antenatal detection, and both antenatal and postnatal therapies that target the key pathophysiological mechanisms underlying altered multi organ structure and function must be considered critical research areas.

\section{AUTHOR CONTRIBUTIONS}

$\mathrm{AM}$ and BA critically researched literature, co-wrote the first draft of the manuscript and approved the final version. MC-M, GJ, GP, and SM reviewed the manuscript, contributed to various sections and approved the final version.

\section{ACKNOWLEDGMENTS}

The authors wish to thank their funding supports: National Health and Medical Research Council (NH\&MRC) project grant, Cerebral Palsy Alliance grant, Royal Australasian College of Physicians Foundation Fellowship (AM); NH\&MRC Research Fellowships (GP and SM), National Heart Foundation of Australia (GP), Australian Research Council Future Fellowship (SM) and the Victorian Government's Operational Infrastructure Support Program. 


\section{REFERENCES}

1. Gordijn SJ, Beune IM, Thilaganathan B, Papageorghiou A, Baschat AA, Baker PN, et al. Consensus definition of fetal growth restriction: a Delphi procedure. Ultrasound Obstetr Gynecol. (2016) 48:333-9. doi: 10.1002/uog. 15884

2. McCowan LM, Figueras F, Anderson NH. Evidence-based national guidelines for the management of suspected fetal growth restriction: comparison, consensus, and controversy. Am J Obstetr Gynecol. (2018) 218:S855-68. doi: 10.1016/j.ajog.2017.12.004

3. Owens JA. Endocrine and substrate control of fetal growth: placental and maternal influences and insulin-like growth factors. Reprod Fertil Dev. (1991) 3:501-17. doi: 10.1071/RD9910501

4. Vorherr H. Factors influencing fetal growth. Am J Obstetr Gynecol. (1982) 142:577-88. doi: 10.1016/0002-9378(82)90765-7

5. Sharma D, Shastri S, Sharma P. Intrauterine growth restriction: antenatal and postnatal aspects. clinical medicine insights. Pediatrics (2016) 10:67-83. doi: 10.4137/CMPed.S40070

6. Burton GJ, Jauniaux E. Pathophysiology of placental-derived fetal growth restriction. Am J Obstetr Gynecol. (2018) 218:S745-61. doi: 10.1016/j.ajog.2017.11.577

7. Ghidini A. Idiopathic fetal growth restriction: a pathophysiologic approach. Obstetr Gynecol Survey (1996) 51:376-82. doi: 10.1097/00006254-199606000-00023

8. Figueras F, Gratacos E. An integrated approach to fetal growth restriction. Best Pract Res Clin Obstet Gynaecol. (2017) 38:48-58. doi: 10.1016/j.bpobgyn.2016.10.006

9. Helwig JT, Parer JT, Kilpatrick SJ, Laros RK Jr. Umbilical cord blood acidbase state: what is normal? Am J Obstetr Gynecol. (1996) 174:1807-12. discussion: 1812-4.

10. Arikan GM, Scholz HS, Petru E, Haeusler MC, Haas J, Weiss PA. Cord blood oxygen saturation in vigorous infants at birth: what is normal? BJOG (2000) 107:987-94. doi: 10.1111/j.1471-0528.2000.tb10401.x

11. Fowden AL, Forhead AJ. Endocrine mechanisms of intrauterine programming. Reproduction (2004) 127:515-26. doi: 10.1530/rep.1.00033

12. Murphy VE, Smith R, Giles WB, Clifton VL. Endocrine regulation of human fetal growth: the role of the mother, placenta, and fetus. Endocrine Rev. (2006) 27:141-69. doi: 10.1210/er.2005-0011

13. Agrogiannis GD, Sifakis S, Patsouris ES, Konstantinidou AE. Insulin-like growth factors in embryonic and fetal growth and skeletal development (Review). Mol Med Reports (2014) 10:579-84. doi: 10.3892/mmr.2014.2258

14. Netchine I, Azzi S, Le Bouc Y, Savage MO. IGF1 molecular anomalies demonstrate its critical role in fetal, postnatal growth and brain development. Best Pract ResClin Endocrinol Metab. (2011) 25:181-90. doi: 10.1016/j.beem.2010.08.005

15. Morris RK, Bilagi A, Devani P, Kilby MD. Association of serum PAPP-A levels in first trimester with small for gestational age and adverse pregnancy outcomes: systematic review and meta-analysis. Prenatal Diagnosis (2017) 37:253-65. doi: 10.1002/pd.5001

16. Spiroski AM, Oliver MH, Jaquiery AL, Prickett CR, Espiner EA, Harding JE, et al. Postnatal effects of intrauterine treatment of the growth-restricted ovine fetus with intra-amniotic insulin-like growth factor-1. J Physiol (2017) 596:5925-45. doi: 10.1113/JP274999

17. Waters MJ, Kaye PL. The role of growth hormone in fetal development. Growth Horm IGF Res. (2002) 12:137-46. doi: 10.1016/S1096-6374(02)00018-7

18. Romejko-Wolniewicz E, Teliga-Czajkowska J, Czajkowski K. Antenatal steroids: can we optimize the dose? Curr Opin Obstetr Gynecol. (2014) 26:77-82. doi: 10.1097/GCO.0000000000000047

19. Wallace EM, Baker LS. Effect of antenatal betamethasone administration on placental vascular resistance. Lancet (1999) 353:1404-7. doi: 10.1016/S0140-6736(98)08229-4

20. Kim WJ, Han YS, Ko HS, Park IY, Shin JC, Wie JH. Antenatal corticosteroids and outcomes of preterm small-for-gestational-age neonates in a single medical center. Obstetr Gynecol Sci. (2018) 61:7-13. doi: 10.5468/ogs.2018.61.1.7

21. Miller SL, Supramaniam VG, Jenkin G, Walker DW, Wallace EM. Cardiovascular responses to maternal betamethasone administration in the intrauterine growth-restricted ovine fetus. Am J Obstetr Gynecol. (2009) 201:613.e1-8. doi: 10.1016/j.ajog.2009.07.028

22. Miller SL, Chai M, Loose J, Castillo-Melendez M, Walker DW, Jenkin $\mathrm{G}$, et al. The effects of maternal betamethasone administration on the intrauterine growth-restricted fetus. Endocrinology (2007) 148:1288-95. doi: $10.1210 /$ en.2006-1058

23. Giussani DA. The fetal brain sparing response to hypoxia: physiological mechanisms. J Physiol. (2016) 594:1215-30. doi: 10.1113/JP271099

24. Morrison JL. Sheep models of intrauterine growth restriction: fetal adaptations and consequences. Clin Exp Pharmacol Physiol. (2008) 35:73043. doi: 10.1111/j.1440-1681.2008.04975.x

25. Schreuder MF, Nauta J. Prenatal programming of nephron number and blood pressure. Kidney Int. (2007) 72:265-8. doi: 10.1038/sj.ki.5002307

26. Miller SL, Wallace EM. Effect of antenatal steroids on haemodynamics in the normally grown and growth restricted fetus. Curr Pediatr Rev. (2013) 9:67-74. doi: 10.2174/1573396311309010014

27. Suhag A, Berghella V. Intrauterine Growth Restriction (IUGR): Etiology and Diagnosis. Curr Obstetr Gynecol Rep. (2013) 2:102-11. doi: 10.1007/s13669-013-0041-z

28. Miller SL, Huppi PS, Mallard C. The consequences of fetal growth restriction on brain structure and neurodevelopmental outcome. J Physiol. (2016) 594:807-23. doi: 10.1113/JP271402

29. Romo A, Carceller R, Tobajas J. Intrauterine growth retardation (IUGR): epidemiology and etiology. Pediatr Endocrinol Rev. (2009) 6(Suppl. 3):332-6.

30. de Onis M, Blossner M, Villar J. Levels and patterns of intrauterine growth retardation in developing countries. Eur J Clin Nutr. (1998) 52(Suppl. 1):S515.

31. Baschat AA. Planning management and delivery of the growthrestricted fetus. Best Pract Res Clin Obstetr Gynaecol. (2018) 49:53-65. doi: 10.1016/j.bpobgyn.2018.02.009

32. Lappen JR, Myers SA. The systematic error in the estimation of fetal weight and the underestimation of fetal growth restriction. Am J Obstetr Gynecol. (2017) 216:477-83. doi: 10.1016/j.ajog.2017.02.013

33. Ernst SA, Brand T, Reeske A, Spallek J, Petersen K, Zeeb H. Care-related and maternal risk factors associated with the antenatal nondetection of intrauterine growth restriction: a case-control study from Bremen, Germany. BioMed Res Int. (2017) 2017:1746146. doi: 10.1155/2017/1746146

34. Chauhan SP, Beydoun H, Chang E, Sandlin AT, Dahlke JD, Igwe E, et al. Prenatal detection of fetal growth restriction in newborns classified as small for gestational age: correlates and risk of neonatal morbidity. Am J Perinatol. (2014) 31:187-94. doi: 10.1055/s-0033-1343771

35. Callec R, Lamy C, Perdriolle-Galet E, Patte C, Heude B, Morel O. Impact on obstetric outcome of third-trimester screening for small-forgestational-age fetuses. Ultrasound Obstetr Gynecol. (2015) 46:216-20. doi: $10.1002 /$ uog. 14755

36. Larkin JC, Chauhan SP, Simhan HN. Small for gestational age: the differential mortality when detected versus undetected antenatally. Am J Perinatol. (2017) 34:409-14. doi: 10.1055/s-0036-1592132

37. Zeitlin J, Ancel PY, Saurel-Cubizolles MJ, Papiernik E. The relationship between intrauterine growth restriction and preterm delivery: an empirical approach using data from a European case-control study. BJOG (2000) 107:750-8. doi: 10.1111/j.1471-0528.2000.tb13336.x

38. Parker SE, Werler MM. Epidemiology of ischemic placental disease: a focus on preterm gestations. Semin Perinatol. (2014) 38:133-8. doi: 10.1053/j.semperi.2014.03.004

39. Monier I, Ancel PY, Ego A, Jarreau PH, Lebeaux C, Kaminski M, et al. Fetal and neonatal outcomes of preterm infants born before 32 weeks of gestation according to antenatal vs postnatal assessments of restricted growth. Am J Obstetr Gynecol. (2017) 216:516.e1-e10. doi: 10.1016/j.ajog.2017.02.001

40. Ananth CV, Friedman AM. Ischemic placental disease and risks of perinatal mortality and morbidity and neurodevelopmental outcomes. Semin Perinatol. (2014) 38:151-8. doi: 10.1053/j.semperi.2014.03.007

41. Bukowski R, Hansen NI, Willinger M, Reddy UM, Parker CB, Pinar $\mathrm{H}$, et al. Fetal growth and risk of stillbirth: a population-based casecontrol study. PLoS Med. (2014) 11:e1001633. doi: 10.1371/journal.pmed.10 01633

42. Malacova E, Regan A, Nassar N, Raynes-Greenow C, Leonard H, Srinivasjois $\mathrm{R}$, et al. Risk of stillbirth, preterm delivery, and fetal growth restriction 
following exposure in a previous birth: systematic review and meta-analysis. BJOG (2018) 125:183-92. doi: 10.1111/1471-0528.14906

43. Gardosi J, Kady SM, McGeown P, Francis A, Tonks A. Classification of stillbirth by relevant condition at death (ReCoDe): population based cohort study. BMJ (2005) 331:1113-7. doi: 10.1136/bmj.38629.587639.7C

44. Victorian Perinatal Services Performance Indicators, 2012-2013. Available online at: www.health.vic.gov.au/CCOPMM

45. Sasi A, Abraham V, Davies-Tuck M, Polglase GR, Jenkin G, Miller SL, et al. Impact of intrauterine growth restriction on preterm lung disease. Acta Paediatr. (2015) 104:e552-6. doi: 10.1111/apa.13220

46. Marzouk A, Filipovic-Pierucci A, Baud O, Tsatsaris V, Ego A, Charles A, et al. Prenatal and post-natal cost of small for gestational age infants: a national study. BMC Health Serv Res. (2017) 17:221. doi: 10.1186/s12913-017-2155-x

47. Lim G, Tracey J, Boom N, Karmakar S, Wang J, Berthelot JM, et al. CIHI survey: hospital costs for preterm and small-for-gestational age babies in Canada. Healthcare Q. (2009) 12:20-4. doi: 10.12927/hcq.2013.21121

48. Gephart SM, Hanson CK. Preventing necrotizing enterocolitis with standardized feeding protocols: not only possible, but imperative. Adv Neonatal Care (2013) 13:48-54. doi: 10.1097/ANC.0b013e31827ece0a

49. Bozzetti V, Tagliabue PE. Enteral feeding of intrauterine growth restriction preterm infants: theoretical risks and practical implications. La Pediatria Medica e Chirurgica (2017) 39:160. doi: 10.4081/pmc.2017.160

50. Ahamed MF, Dar P, Vega M, Kim M, Gao Q, Havranek T. Early feeding tolerance in small for gestational age infants with normal versus abnormal antenatal Doppler characteristics. J Neonatal-Perinatal Med. (2017) 10:4348. doi: 10.3233/NPM-1682

51. Bozzetti V, Paterlini G, De Lorenzo P, Gazzolo D, Valsecchi MG, Tagliabue PE. Impact of continuous vs bolus feeding on splanchnic perfusion in very low birth weight infants: a randomized trial. J Pediatr. (2016) 176:86-92.e2. doi: 10.1016/j.jpeds.2016.05.031

52. Fortune PM, Wagstaff M, Petros AJ. Cerebro-splanchnic oxygenation ratio (CSOR) using near infrared spectroscopy may be able to predict splanchnic ischaemia in neonates. Intensive Care Med. (2001) 27:1401-7. doi: 10.1007/s001340100994

53. Kempley S, Gupta N, Linsell L, Dorling J, McCormick K, Mannix P, et al. Feeding infants below 29 weeks' gestation with abnormal antenatal Doppler: analysis from a randomised trial. Arch Dis Childhood. (2014) 99:F6-F11. doi: 10.1136/archdischild-2013-304393

54. Leaf A, Dorling J, Kempley S, McCormick K, Mannix P, Linsell L, et al. Early or delayed enteral feeding for preterm growthrestricted infants: a randomized trial. Pediatrics (2012) 129:e1260-8. doi: 10.1542/peds.2011-2379

55. Zecca E, Costa S, Barone G, Giordano L, Zecca C, Maggio L. Proactive enteral nutrition in moderately preterm small for gestational age infants: a randomized clinical trial. J Pediatr. (2014) 165:1135-1139.e1. doi: 10.1016/j.jpeds.2014.08.065

56. Longo S, Borghesi A, Tzialla C, Stronati M. IUGR and infections. Early Hum Dev. (2014) 90(Suppl. 1):S42-4. doi: 10.1016/S0378-3782(14)70014-3

57. Lee JW, VanderVeen D, Allred EN, Leviton A, Dammann O. Prethreshold retinopathy in premature infants with intrauterine growth restriction. Acta Paediatr (2015) 104:27-31. doi: 10.1111/apa.12799

58. Aisa MC, Cappuccini B, Barbati A, Orlacchio A, Baglioni M, Di Renzo GC. Biochemical parameters of renal impairment/injury and surrogate markers of nephron number in intrauterine growth-restricted and preterm neonates at 30-40 days of postnatal corrected age. Pediatr Nephrol. (2016) 31:2277-87. doi: 10.1007/s00467-016-3484-4

59. Barbati A, Cappuccini B, Aisa MC, Grasselli C, Zamarra M, Bini V, et al. Increased urinary cystatin-C levels correlate with reduced renal volumes in neonates with intrauterine growth restriction. Neonatology (2016) 109:15460. doi: $10.1159 / 000441273$

60. Menendez-Castro C, Rascher W, Hartner A. Intrauterine growth restriction - impact on cardiovascular diseases later in life. Mol Cell Pediatr. (2018) 5:4. doi: 10.1186/s40348-018-0082-5

61. Barker DJ, Bull AR, Osmond C, Simmonds SJ. Fetal and placental size and risk of hypertension in adult life. BMJ (1990) 301:259-62. doi: 10.1136/bmj.301.6746.259

62. Oros D, Figueras F, Cruz-Martinez R, Meler E, Munmany M, Gratacos E. Longitudinal changes in uterine, umbilical and fetal cerebral Doppler indices in late-onset small-for-gestational age fetuses. Ultrasound Obstetr Gynecol. (2011) 37:191-5. doi: 10.1002/uog.7738

63. Ghosh GS, Gudmundsson S. Uterine and umbilical artery Doppler are comparable in predicting perinatal outcome of growth-restricted fetuses. BJOG (2009) 116:424-30. doi: 10.1111/j.1471-0528.2008.02057.x

64. Hassan WA, Brockelsby J, Alberry M, Fanelli T, Wladimiroff J, Lees CC. Cardiac function in early onset small for gestational age and growth restricted fetuses. Eur J Obstet Gynecol Reprod Biol. (2013) 171:262-5. doi: 10.1016/j.ejogrb.2013.09.020

65. Perez-Cruz M, Cruz-Lemini M, Fernandez MT, Parra JA, Bartrons J, Gomez-Roig MD, et al. Fetal cardiac function in late-onset intrauterine growth restriction vs small-for-gestational age, as defined by estimated fetal weight, cerebroplacental ratio and uterine artery Doppler. Ultrasound Obstet Gynecol. (2015) 46:465-71. doi: 10.1002/uog.14930

66. Crispi F, Hernandez-Andrade E, Pelsers MM, Plasencia W, BenavidesSerralde JA, Eixarch E, et al. Cardiac dysfunction and cell damage across clinical stages of severity in growth-restricted fetuses. Am J Obstetr Gynecol. (2008) 199:254.e1-8. doi: 10.1016/j.ajog.2008.06.056

67. Menendez-Castro C, Fahlbusch F, Cordasic N, Amann K, Munzel K, Plank C, et al. Early and late postnatal myocardial and vascular changes in a protein restriction rat model of intrauterine growth restriction. PLOS ONE (2011) 6:e20369. doi: 10.1371/journal.pone.0020369

68. Barry JS, Rozance PJ, Brown LD, Anthony RV, Thornburg KL, Hay WW Jr. Increased fetal myocardial sensitivity to insulin-stimulated glucose metabolism during ovine fetal growth restriction. Exp Biol Med (Maywood) (2016) 241:839-47. doi: 10.1177/1535370216632621

69. Poudel R, McMillen IC, Dunn SL, Zhang S, Morrison JL. Impact of chronic hypoxemia on blood flow to the brain, heart, and adrenal gland in the lategestation IUGR sheep fetus. Am J Physiol Regul Integr Comp Physiol. (2015) 308:R151-62. doi: 10.1152/ajpregu.00036.2014

70. Masoumy EP, Sawyer AA, Sharma S, Patel JA, Gordon MK, Regnault $\mathrm{RH}$, et al. The lifelong impact of fetal growth restriction on cardiac development. Pediatr Res. (2018) 84:537-44. doi: 10.1038/s41390-01 8-0069-x

71. Bubb KJ, Cock ML, Black MJ, Dodic M, Boon WM, Parkington HC, et al. Intrauterine growth restriction delays cardiomyocyte maturation and alters coronary artery function in the fetal sheep. J Physiol. (2007) 578:871-81. doi: 10.1113/jphysiol.2006.121160

72. Opitz CA, Linke WA. Plasticity of cardiac titin/connectin in heart development. J Muscle Res Cell Motil. (2005) 26:333-42. doi: 10.1007/s10974-005-9040-7

73. Torre I, Gonzalez-Tendero A, Garcia-Canadilla P, Crispi F, Garcia-Garcia F, Bijnens B, et al. Permanent cardiac sarcomere changes in a rabbit model of intrauterine growth restriction. PLoS ONE (2014) 9:e113067. doi: 10.1371/journal.pone. 0113067

74. Iruretagoyena JI, Gonzalez-Tendero A, Garcia-Canadilla P, Amat-Roldan I, Torre I, Nadal A, et al. Cardiac dysfunction is associated with altered sarcomere ultrastructure in intrauterine growth restriction. Am J Obstet Gynecol. (2014) 210:550.e1-7. doi: 10.1016/j.ajog.2014.01.023

75. Tare M, Parkington HC, Wallace EM, Sutherland AE, Lim R, Yawno $\mathrm{T}$, et al. Maternal melatonin administration mitigates coronary stiffness and endothelial dysfunction, and improves heart resilience to insult in growth restricted lambs. J Physiol. (2014) 592:2695-709. doi: 10.1113/jphysiol.2014.270934

76. Brain KL, Allison BJ, Niu Y, Cross CM, Itani N, Kane AD, et al. Induction of controlled hypoxic pregnancy in large mammalian species. Physiol Rep. (2015) 3:e12614. doi: 10.14814/phy2.12614

77. Sehgal A, Allison BJ, Gwini SM, Miller SL, Polglase GR. Cardiac morphology and function in preterm growth restricted infants: relevance for clinical sequelae. J Pediatr. (2017) 188:128-134.e2. doi: 10.1016/j.jpeds.2017. 05.076

78. Allison BJ, Brain KL, Niu Y, Kane AD, Herrera EA, Thakor AS, et al. Fetal in vivo continuous cardiovascular function during chronic hypoxia. J Physiol. (2016) 594:1247-64. doi: 10.1113/JP271091

79. Allison BJ, Kaandorp JJ, Kane AD, Camm EJ, Lusby C, Cross CM, et al. Divergence of mechanistic pathways mediating cardiovascular aging and developmental programming of cardiovascular disease. FASEB J. (2016) 30:1968-75. doi: $10.1096 / f j .201500057$ 
80. Sehgal A, Allison BJ, Gwini SM, Menahem S, Miller SL, Polglase GR. Vascular aging and cardiac maladaptation in growth-restricted preterm infants. $J$ Perinatol. (2017) 38:92-7. doi: 10.1038/jp.2017.135

81. Dodson RB, Rozance PJ, Petrash CC, Hunter KS, Ferguson VL. Thoracic and abdominal aortas stiffen through unique extracellular matrix changes in intrauterine growth restricted fetal sheep. Am J Physiol Heart Circ Physiol. (2014) 306:H429-37. doi: 10.1152/ajpheart.004 72.2013

82. Kuo AH, Li C, Huber HF, Clarke GD, Nathanielsz PW. Intrauterine growth restriction results in persistent vascular mismatch in adulthood. J Physiol. (2017) 596:5777-90. doi: 10.1113/JP275139

83. Canas D, Herrera EA, Garcia-Herrera C, Celentano D, Krause BJ. Fetal growth restriction induces heterogeneous effects on vascular biomechanical and functional properties in guinea pigs (Cavia porcellus). Front Physiol. (2017) 8:144. doi: 10.3389/fphys.2017.00144

84. Martyn CN, Greenwald SE. Impaired synthesis of elastin in walls of aorta and large conduit arteries during early development as an initiating event in pathogenesis of systemic hypertension. Lancet (1997) 350:953-5. doi: 10.1016/S0140-6736(96)10508-0

85. Dodson RB, Miller TA, Powers K, Yang Y, Yu B, Albertine KH, et al. Intrauterine growth restriction influences vascular remodeling and stiffening in the weanling rat more than sex or diet. Am J Physiol Heart Circ Physiol. (2017) 312:H250-64. doi: 10.1152/ajpheart.00610.2016

86. Fouzas S, Karatza AA, Davlouros PA, Chrysis D, Alexopoulos D, Mantagos S, et al. Neonatal cardiac dysfunction in intrauterine growth restriction. Pediatr Res. (2014) 75:651-7. doi: 10.1038/pr.2014.22

87. Cohen E, Whatley C, Wong FY, Wallace EM, Mockler JC, Odoi A, et al. Effects of foetal growth restriction and preterm birth on cardiac morphology and function during infancy. Acta Paediatr. (2017) 107:450-5. doi: 10.1111/apa.14144

88. Verburg BO, Jaddoe VW, Wladimiroff JW, Hofman A, Witteman JC, Steegers EA. Fetal hemodynamic adaptive changes related to intrauterine growth: the Generation R Study. Circulation (2008) 117:649-59. doi: 10.1161/CIRCULATIONAHA.107.709717

89. Roseboom T, de Rooij S, Painter R. The Dutch famine and its longterm consequences for adult health. Early Hum Dev. (2006) 82:485-91. doi: 10.1016/j.earlhumdev.2006.07.001

90. Leon DA, Lithell HO, Vagero D, Koupilova I, Mohsen R, Berglund L, et al. Reduced fetal growth rate and increased risk of death from ischaemic heart disease: cohort study of 15000 Swedish men and women born 1915-29. BMJ (1998) 317:241-5. doi: 10.1136/bmj.317.7153.241

91. Fukuoka H. DOHaD (Developmental Origins of Health and Disease) and Birth Cohort Research. J Nutr Sci Vitaminol. (2015) 61(Suppl.):S2-4. doi: 10.3177/jnsv.61.S2

92. Skilton MR, Evans N, Griffiths KA, Harmer JA, Celermajer DS. Aortic wall thickness in newborns with intrauterine growth restriction. Lancet (2005) 365:1484-6. doi: 10.1016/S0140-6736(05)66419-7

93. Zanardo V, Fanelli T, Weiner G, Fanos V, Zaninotto M, Visentin S, et al. Intrauterine growth restriction is associated with persistent aortic wall thickening and glomerular proteinuria during infancy. Kidney Int. (2011) 80:119-23. doi: 10.1038/ki.2011.99

94. Singhal A, Kattenhorn M, Cole TJ, Deanfield J, Lucas A. Preterm birth, vascular function, and risk factors for atherosclerosis. Lancet (2001) 358:1159-60. doi: 10.1016/S0140-6736(01)06276-6

95. Kotecha SJ, Watkins WJ, Heron J, Henderson J, Dunstan FD, Kotecha S. Spirometric lung function in school-age children: effect of intrauterine growth retardation and catch-up growth. Am J Respirat Crit Care Med. (2010) 181:969-74. doi: 10.1164/rccm.200906-0897OC

96. Check J, Gotteiner N, Liu X, Su E, Porta N, Steinhorn R, et al. Fetal growth restriction and pulmonary hypertension in premature infants with bronchopulmonary dysplasia. J Perinatol. (2013) 33:553-7. doi: $10.1038 /$ jp.2012.164

97. Sehgal A, Gwini SM, Menahem S, Allison BJ, Miller SL, Polglase GR. Preterm growth restriction and bronchopulmonary dysplasia: the vascular hypothesis and related physiology. J Physiol. (2018). doi: 10.1113/JP276040. [Epub ahead of print].

98. Ronkainen E, Dunder T, Kaukola T, Marttila R, Hallman M. Intrauterine growth restriction predicts lower lung function at school age in children born very preterm. Arch Dis Childhood (2016) 101:F412-7. doi: 10.1136/archdischild-2015-308922

99. Barker DJ, Godfrey KM, Fall C, Osmond C, Winter PD, Shaheen SO. Relation of birth weight and childhood respiratory infection to adult lung function and death from chronic obstructive airways disease. BMJ (1991) 303:671-5. doi: 10.1136/bmj.303.6804.671

100. McGillick EV, Orgeig S, Allison BJ, Brain KL, Niu Y, Itani N, et al. Maternal chronic hypoxia increases expression of genes regulating lung liquid movement and surfactant maturation in male fetuses in late gestation. J Physiol. (2017) 595:4329-50. doi: 10.1113/JP273842

101. Ambalavanan N, Nicola T, Hagood J, Bulger A, Serra R, MurphyUllrich J, et al. Transforming growth factor-beta signaling mediates hypoxia-induced pulmonary arterial remodeling and inhibition of alveolar development in newborn mouse lung. Am J Physiol. (2008) 295:L86-95. doi: 10.1152/ajplung.00534.2007

102. Polglase GR, Barbuto J, Allison BJ, Yawno T, Sutherland AE, Malhotra A, et al. Effects of antenatal melatonin therapy on lung structure in growth-restricted newborn lambs. J Appl Physiol. (2017) 123:1195-203. doi: 10.1152/japplphysiol.00783.2016

103. Allison BJ, Hooper SB, Coia E, Zahra VA, Jenkin G, Malhotra A, et al. Ventilation-induced lung injury is not exacerbated by growth restriction in preterm lambs. Am J Physiol. (2016) 310:L213-23. doi: 10.1152/ajplung.00328.2015

104. Sutherland AE, Crossley KJ, Allison BJ, Jenkin G, Wallace EM, Miller SL. The effects of intrauterine growth restriction and antenatal glucocorticoids on ovine fetal lung development. Pediatr Res. (2012) 71:689-96. doi: 10.1038/pr.2012.19

105. Maritz GS, Cock ML, Louey S, Joyce BJ, Albuquerque CA, Harding R. Effects of fetal growth restriction on lung development before and after birth: a morphometric analysis. Pediatr Pulmonol. (2001) 32:201-10. doi: 10.1002/ppul.1109

106. Gortner L, Hilgendorff A, Bahner T, Ebsen M, Reiss I, Rudloff S. Hypoxiainduced intrauterine growth retardation: effects on pulmonary development and surfactant protein transcription. Biol Neonate (2005) 88:129-35. doi: $10.1159 / 000085895$

107. Orgeig S, Crittenden TA, Marchant C, McMillen IC, Morrison JL. Intrauterine growth restriction delays surfactant protein maturation in the sheep fetus. Am J Physiol. (2010) 298:L575-83. doi: 10.1152/ajplung.00226.2009

108. Zhu MY, Milligan N, Keating S, Windrim R, Keunen J, Thakur V, et al. The hemodynamics of late-onset intrauterine growth restriction by MRI. Am J Obstetr Gynecol. (2016) 214:367.e1-367.e17. doi: 10.1016/j.ajog.2015. 10.004

109. Kiserud T, Ebbing C, Kessler J, Rasmussen S. Fetal cardiac output, distribution to the placenta and impact of placental compromise. Ultrasound Obstetr Gynecol. (2006) 28:126-36. doi: 10.1002/uog.2832

110. Polglase GR, Allison BJ, Coia E, Li A, Jenkin G, Malhotra A, et al. Altered cardiovascular function at birth in growth-restricted preterm lambs. Pediatr Res. (2016) 80:538-46. doi: 10.1038/pr.2016.104

111. Hooper SB, Harding R. Fetal lung liquid: a major determinant of the growth and functional development of the fetal lung. Clin Exp Pharmacol Physiol. (1995) 22:235-47. doi: 10.1111/j.1440-1681.1995.tb01988.x

112. Harding R. Fetal pulmonary development: the role of respiratory movements. Equine Vet J Suppl. (1997) 32-9. doi: 10.1111/j.2042-3306.1997.tb05076.x

113. Filby CE, Hooper SB, Wallace MJ. Partial pulmonary embolization disrupts alveolarization in fetal sheep. Respir Res. (2010) 11:42. doi: 10.1186/1465-9921-11-42

114. Thebaud B, Abman SH. Bronchopulmonary dysplasia: where have all the vessels gone? Roles of angiogenic growth factors in chronic lung disease. Am J Respir Crit Care Med. (2007) 175:978-85. doi: 10.1164/rccm.200611-1660PP

115. Galambos C, Ng YS, Ali A, Noguchi A, Lovejoy S, D'Amore PA, et al. Defective pulmonary development in the absence of heparin-binding vascular endothelial growth factor isoforms. Am J Respir Cell Mol Biol. (2002) 27:194-203. doi: 10.1165/ajrcmb.27.2.4703

116. Rozance PJ, Seedorf GJ, Brown A, Roe G, O’Meara MC, Gien J, et al. Intrauterine growth restriction decreases pulmonary alveolar and vessel growth and causes pulmonary artery endothelial cell 
dysfunction in vitro in fetal sheep. Am J Physiol. (2011) 301:L860-71. doi: 10.1152/ajplung.00197.2011

117. Karadag A, Sakurai R, Wang Y, Guo P, Desai M, Ross MG, et al. Effect of maternal food restriction on fetal rat lung lipid differentiation program. Pediatr Pulmonol. (2009) 44:635-44. doi: 10.1002/ppul.21030

118. Mestan KK, Check J, Minturn L, Yallapragada S, Farrow KN, Liu X, et al. Placental pathologic changes of maternal vascular underperfusion in bronchopulmonary dysplasia and pulmonary hypertension. Placenta (2014) 35:570-4. doi: 10.1016/j.placenta.2014.05.003

119. Eriksson L, Haglund B, Odlind V, Altman M, Ewald U, Kieler H. Perinatal conditions related to growth restriction and inflammation are associated with an increased risk of bronchopulmonary dysplasia. Acta Paediatr. (2015) 104:259-63. doi: 10.1111/apa.12888

120. Gagliardi L, Rusconi F, Da Frè M, Mello G, Carnielli V, Di Lallo D, et al. Pregnancy disorders leading to very preterm birth influence neonatal outcomes: results of the population-based ACTION cohort study. Pediatr Res. (2013) 73:794-801. doi: 10.1038/pr.2013.52

121. Lio A, Rosati P, Pastorino R, Cota F, Tana M, Tirone C, et al. Fetal Doppler velocimetry and bronchopulmonary dysplasia risk among growth-restricted preterm infants: an observational study. BMJ Open (2017) 7:e015232. doi: 10.1136/bmjopen-2016-015232

122. Papamatheakis DG, Chundu M, Blood AB, Wilson SM. Prenatal programming of pulmonary hypertension induced by chronic hypoxia or ductal ligation in sheep. Pulmonary Circ. (2013) 3:757-80. doi: $10.1086 / 674767$

123. Berkelhamer SK, Mestan KK, Steinhorn RH. Pulmonary hypertension in bronchopulmonary dysplasia. Semin Perinatol. (2013) 37:124-31. doi: 10.1053/j.semperi.2013.01.009

124. Joss-Moore LA, Wang Y, Yu X, Campbell MS, Callaway CW, McKnight RA, et al. IUGR decreases elastin mRNA expression in the developing rat lung and alters elastin content and lung compliance in the mature rat lung. Physiol Genom. (2011) 43:499-505. doi: 10.1152/physiolgenomics.00183.2010

125. Lopuhaä CE, Roseboom TJ, Osmond C, Barker DJ, Ravelli AC, Bleker OP, et al. Atopy, lung function, and obstructive airways disease after prenatal exposure to famine. Thorax (2000) 55:555-61. doi: 10.1136/thorax.55.7.555

126. Egana-Ugrinovic G, Sanz-Cortes M, Figueras F, Bargallo N, Gratacos E. Differences in cortical development assessed by fetal MRI in late-onset intrauterine growth restriction. Am J Obstetr Gynecol. (2013) 209:126.e1-8. doi: 10.1016/j.ajog.2013.04.008

127. Huppi PS. Cortical development in the fetus and the newborn: advanced MR techniques. Top Magn Reson. Imaging (2011) 22:33-8. doi: 10.1097/RMR.0b013e3182416f78

128. Arthurs OJ, Rega A, Guimiot F, Belarbi N, Rosenblatt J, Biran V, et al. Diffusion-weighted magnetic resonance imaging of the fetal brain in intrauterine growth restriction. Ultrasound Obstetr Gynecol. (2017) 50:7987. doi: 10.1002/uog. 17318

129. Tolsa CB, Zimine S, Warfield SK, Freschi M, Sancho Rossignol A, Lazeyras F, et al. Early alteration of structural and functional brain development in premature infants born with intrauterine growth restriction. Pediatr. Res. (2004) 56:132-8. doi: 10.1203/01.PDR.0000128983.54614.7E

130. Ramenghi LA, Martinelli A, De Carli A, Brusati V, Mandia L, Fumagalli $M$, et al. Cerebral maturation in IUGR and appropriate for gestational age preterm babies. Reprod Sci. (2011) 18:469-75. doi: 10.1177/1933719110388847

131. Lodygensky GA, Seghier ML, Warfield SK, Tolsa CB, Sizonenko $\mathrm{S}$, Lazeyras $\mathrm{F}$, et al. Intrauterine growth restriction affects the preterm infant's hippocampus. Pediatr Res. (2008) 63:438-43. doi: 10.1203/PDR.0b013e318165c005

132. Bruno CJ, Bengani S, Gomes WA, Brewer M, Vega M, Xie X, et al. MRI differences associated with intrauterine growth restriction in preterm infants. Neonatology (2017) 111:317-23. doi: 10.1159/000453576

133. Batalle D, Munoz-Moreno E, Tornador C, Bargallo N, Deco G, Eixarch $\mathrm{E}$, et al. Altered resting-state whole-brain functional networks of neonates with intrauterine growth restriction. Cortex (2016) 77:119-31. doi: 10.1016/j.cortex.2016.01.012

134. van de Looij Y, Dean JM, Gunn AJ, Huppi PS, Sizonenko SV. Advanced magnetic resonance spectroscopy and imaging techniques applied to brain development and animal models of perinatal injury. Int J Dev Neurosci. (2015) 45:29-38. doi: 10.1016/j.ijdevneu.2015.03.009

135. Malhotra A, Ditchfield M, Fahey MC, Castillo-Melendez M, Allison BJ, Polglase GR, et al. Detection and assessment of brain injury in the growth-restricted fetus and neonate. Pediatr Res. (2017) 82:184-93. doi: 10.1038/pr.2017.37

136. Malhotra A, Yahya Z, Sasi A, Jenkin G, Ditchfield M, Polglase GR, et al. Does fetal growth restriction lead to increased brain injury as detected by neonatal cranial ultrasound in premature infants? J Paediatr Child Health (2015) 51:1103-8. doi: 10.1111/jpc.12910

137. Krishnamurthy MB, Popiel A, Malhotra A. Screening investigations in small-for-gestational-age near-term and term infants. Eur J Pediatr. (2017) 176:1707-12. doi: 10.1007/s00431-017-3031-8

138. McLean G, Hough C, Sehgal A, Ditchfield M, Polglase GR, Miller SL. Threedimensional ultrasound cranial imaging and early neurodevelopment in preterm growth-restricted infants. J Paediatr Child Health (2018) 54:420-5. doi: $10.1111 /$ jpc. 13808

139. Cruz-Martinez R, Tenorio V, Padilla N, Crispi F, Figueras F, Gratacos E. Risk of ultrasound-detected neonatal brain abnormalities in intrauterine growthrestricted fetuses born between 28 and 34 weeks' gestation: relationship with gestational age at birth and fetal Doppler parameters. Ultrasound Obstetr Gynecol. (2015) 46:452-9. doi: 10.1002/uog.14920

140. Padilla N, Falcon C, Sanz-Cortes M, Figueras F, Bargallo N, Crispi F, et al. Differential effects of intrauterine growth restriction on brain structure and development in preterm infants: a magnetic resonance imaging study. Brain Res. (2011) 1382:98-108. doi: 10.1016/j.brainres.2011.01.032

141. Padilla N, Junque C, Figueras F, Sanz-Cortes M, Bargallo N, Arranz A, et al. Differential vulnerability of gray matter and white matter to intrauterine growth restriction in preterm infants at 12 months corrected age. Brain Res. (2014) 1545:1-11. doi: 10.1016/j.brainres.2013.12.007

142. Batalle D, Eixarch E, Figueras F, Munoz-Moreno E, Bargallo N, Illa $\mathrm{M}$, et al. Altered small-world topology of structural brain networks in infants with intrauterine growth restriction and its association with later neurodevelopmental outcome. Neuroimage (2012) 60:1352-66. doi: 10.1016/j.neuroimage.2012.01.059

143. Fischi-Gomez E, Vasung L, Meskaldji DE, Lazeyras F, Borradori-Tolsa C, Hagmann P, et al. Structural brain connectivity in school-age preterm infants provides evidence for impaired networks relevant for higher order cognitive skills and social cognition. Cereb Cortex (2015) 25:2793-805. doi: $10.1093 /$ cercor/bhu073

144. Tanis JC, Schmitz DM, Boelen MR, Casarella L, van den Berg PP, Bilardo $\mathrm{CM}$, et al. Relationship between general movements in neonates who were growth restricted in utero and prenatal Doppler flow patterns. Ultrasound Obstetr Gynecol. (2016) 48:772-8. doi: 10.1002/uog.15903

145. Yerushalmy-Feler A, Marom R, Peylan T, Korn A, Haham A, Mandel $\mathrm{D}$, et al. Electroencephalographic characteristics in preterm infants born with intrauterine growth restriction. J Pediatr. (2014) 164:756-761.e1. doi: 10.1016/j.jpeds.2013.12.030

146. Cohen E, Wong FY, Wallace EM, Mockler JC, Odoi A, Hollis S, et al. EEG power spectrum maturation in preterm fetal growth restricted infants. Brain Res. (2018) 1678:180-6. doi: 10.1016/j.brainres.2017.10.010

147. Arduini D, Rizzo G, Romanini C, Mancuso S. Fetal haemodynamic response to acute maternal hyperoxygenation as predictor of fetal distress in intrauterine growth retardation. BMJ (1989) 298:1561-2. doi: $10.1136 /$ bmj.298.6687.1561

148. Hernandez-Andrade E, Figueroa-Diesel H, Jansson T, Rangel-Nava H, Gratacos E. Changes in regional fetal cerebral blood flow perfusion in relation to hemodynamic deterioration in severely growth-restricted fetuses. Ultrasound Obstetr Gynecol. (2008) 32:71-6. doi: 10.1002/uog.5377

149. Ishii H, Takami T, Fujioka T, Mizukaki N, Kondo A, Sunohara D, et al. Comparison of changes in cerebral and systemic perfusion between appropriate- and small-for-gestational-age infants during the first three days after birth. Brain Dev. (2014) 36:380-7. doi: 10.1016/j.braindev.2013.06.006

150. Hunter DS, Hazel SJ, Kind KL, Owens JA, Pitcher JB, Gatford KL. Programming the brain: common outcomes and gaps in knowledge from animal studies of IUGR. Physiol Behav. (2016) 164:233-48. doi: 10.1016/j.physbeh.2016.06.005 
151. Basilious A, Yager J, Fehlings MG. Neurological outcomes of animal models of uterine artery ligation and relevance to human intrauterine growth restriction: a systematic review. Dev Med Child Neurol. (2015) 57:420-30. doi: 10.1111/dmcn.12599

152. Swanson AM, David AL. Animal models of fetal growth restriction: considerations for translational medicine. Placenta (2015) 36:623-30. doi: 10.1016/j.placenta.2015.03.003

153. McDougall ARA, Wiradjaja V, Azhan A, Li A, Hale N, Wlodek ME, et al. Intrauterine growth restriction alters the postnatal development of the rat cerebellum. Dev Neurosci. (2017) 39:215-27. doi: 10.1159/000470902

154. Alves de Alencar Rocha AK, Allison BJ, Yawno T, Polglase GR, Sutherland AE, Malhotra A, et al. Early- versus late-onset fetal growth restriction differentially affects the development of the fetal sheep brain. Dev Neurosci. (2017) 39:141-55. doi: 10.1159/000456542

155. Eixarch E, Batalle D, Illa M, Munoz-Moreno E, Arbat-Plana A, AmatRoldan I, et al. Neonatal neurobehavior and diffusion MRI changes in brain reorganization due to intrauterine growth restriction in a rabbit model. PLoS ONE (2012) 7:e31497. doi: 10.1371/journal.pone.0031497

156. Ruff CA, Faulkner SD, Rumajogee P, Beldick S, Foltz W, Corrigan J, et al. The extent of intrauterine growth restriction determines the severity of cerebral injury and neurobehavioural deficits in rodents. PLOS ONE (2017) 12:e0184653. doi: 10.1371/journal.pone.0184653

157. Tolcos M, Petratos S, Hirst JJ, Wong F, Spencer SJ, Azhan A, et al. Blocked, delayed, or obstructed: what causes poor white matter development in intrauterine growth restricted infants? Prog Neurobiol. (2017) 154:62-77. doi: 10.1016/j.pneurobio.2017.03.009

158. Bisignano M, Rees S. The effects of intrauterine growth retardation on synaptogenesis and mitochondrial formation in the cerebral and cerebellar cortices of fetal sheep. Int J Dev Neurosci. (1988) 6:453-60. doi: 10.1016/0736-5748(88)90051-2

159. Castillo-Melendez M, Yawno T, Allison BJ, Jenkin G, Wallace EM, Miller SL. Cerebrovascular adaptations to chronic hypoxia in the growth restricted lamb. Int J Dev Neurosci. (2015) 45:55-65. doi: 10.1016/j.ijdevneu.2015.01.004

160. Allison BJ, Hooper SB, Coia E, Jenkin G, Malhotra A, Zahra V, et al. Does growth restriction increase the vulnerability to acute ventilation-induced brain injury in newborn lambs? Implications for future health and disease. J Dev Orig Health Dis. (2017) 8:556-65. doi: 10.1017/S204017441700037X

161. Malhotra A, Castillo-Melendez M, Allison BJ, Sutherland AE, Nitsos I, Pham Y, et al. Neuropathology as a consequence of neonatal ventilation in premature growth restricted lambs. Am J Physiol Regul Integr Comp Physiol. (2018) 315:R1183-1194. doi: 10.1152/ajpregu.00171.2018

162. Blair EM, Nelson KB. Fetal growth restriction and risk of cerebral palsy in singletons born after at least 35 weeks' gestation. Am J Obstetr Gynecol. (2015) 212:520.e1-7. doi: 10.1016/j.ajog.2014.10.1103

163. Morsing E, Asard M, Ley D, Stjernqvist K, Marsal K. Cognitive function after intrauterine growth restriction and very preterm birth. Pediatrics (2011) 127:e874-82. doi: 10.1542/peds.2010-1821

164. Baschat AA. Neurodevelopment after fetal growth restriction. Fetal Diagn Ther. (2014) 36:136-42. doi: 10.1159/000353631

165. MacLennan AH, Thompson SC, Gecz J. Cerebral palsy: causes, pathways, and the role of genetic variants. Am J Obstet Gynecol. (2015) 213:779-88. doi: 10.1016/j.ajog.2015.05.034

166. Report of the Australian Cerebral Palsy Register, Birth Years 1993-2006 (February 2013).

167. Sung IK, Vohr B, Oh W. Growth and neurodevelopmental outcome of very low birth weight infants with intrauterine growth retardation: comparison with control subjects matched by birth weight and gestational age. J Pediatr. (1993) 123:618-24. doi: 10.1016/S0022-3476(05)80965-5

168. Leitner Y, Fattal-Valevski A, Geva R, Eshel R, Toledano-Alhadef H, Rotstein $\mathrm{M}$, et al. Neurodevelopmental outcome of children with intrauterine growth retardation: a longitudinal, 10-year prospective study. J Child Neurol. (2007) 22:580-7. doi: 10.1177/0883073807302605

169. Low JA, Handley-Derry MH, Burke SO, Peters RD, Pater EA, Killen HL, et al. Association of intrauterine fetal growth retardation and learning deficits at age 9 to 11 years. Am J Obstet Gynecol. (1992) 167:1499-505. doi: 10.1016/0002-9378(92)91727-R
170. Geva R, Eshel R, Leitner Y, Fattal-Valevski A, Harel S. Memory functions of children born with asymmetric intrauterine growth restriction. Brain Res. (2006) 1117:186-94. doi: 10.1016/j.brainres.2006.08.004

171. Geva R, Eshel R, Leitner Y, Valevski AF, Harel S. Neuropsychological outcome of children with intrauterine growth restriction: a 9-year prospective study. Pediatrics (2006) 118:91-100. doi: $10.1542 /$ peds.2005-2343

172. Murray E, Fernandes M, Fazel M, Kennedy SH, Villar J, Stein A. Differential effect of intrauterine growth restriction on childhood neurodevelopment: a systematic review. BJOG (2015) 122:1062-72. doi: 10.1111/1471-0528.13435

173. Larroque B, Bertrais S, Czernichow P, Leger J. School difficulties in 20-yearolds who were born small for gestational age at term in a regional cohort study. Pediatrics (2001) 108:111-5. doi: 10.1542/peds.108.1.111

174. Walton RB, Reed LC, Estrada SM, Schmiedecke SS, VillazanaKretzer DL, Napolitano PG, et al. Evaluation of sildenafil and tadalafil for reversing constriction of fetal arteries in a human placenta perfusion model. Hypertension (2018) 72:167-76. doi: 10.1161/HYPERTENSIONAHA.117.10738

175. Khan RN, Hamoud H, Warren A, Wong LF, Arulkumaran S. Relaxant action of sildenafil citrate (Viagra) on human myometrium of pregnancy. Am J Obstetr Gynecol. (2004) 191:315-21. doi: 10.1016/j.ajog.2003.11.005

176. Wareing M, Myers JE, O’Hara M, Baker PN. Sildenafil citrate (Viagra) enhances vasodilatation in fetal growth restriction. J Clin Endocrinol Metab. (2005) 90:2550-5. doi: 10.1210/jc.2004-1831

177. Paauw ND, Terstappen F, Ganzevoort W, Joles JA, Gremmels H, Lely AT, et al. Sildenafil During pregnancy: a preclinical meta-analysis on fetal growth and maternal blood pressure. Hypertension (2017) 70:998-1006. doi: 10.1161/HYPERTENSIONAHA.117.09690

178. Miller SL, Loose JM, Jenkin G, Wallace EM. The effects of sildenafil citrate (Viagra) on uterine blood flow and well being in the intrauterine growth-restricted fetus. Am J Obstetr Gynecol. (2009) 200:102.e1-7. doi: 10.1016/j.ajog.2008.08.029

179. Hawkes N. Trial of Viagra for fetal growth restriction is halted after baby deaths. BMJ (2018) 362:k3247. doi: 10.1136/bmj.k3247

180. Smith GCS. The STRIDER trial: one step forward, one step back. Lancet (2018) 2:80-1. doi: 10.1016/S2352-4642(17)30176-1

181. Pellicer B, Herraiz S, Cauli O, Rodrigo R, Asensi M, Cortijo J, et al. Haemodynamic effects of long-term administration of sildenafil in normotensive pregnant and non-pregnant rats. BJOG (2011) 118:615-23. doi: 10.1111/j.1471-0528.2010.02839.x

182. Spencer R, Ambler G, Brodszki J, Diemert A, Figueras F, Gratacos E, et al. EVERREST prospective study: a 6-year prospective study to define the clinical and biological characteristics of pregnancies affected by severe early onset fetal growth restriction. BMC Preg Childbirth (2017) 17:43. doi: 10.1186/s12884-017-1226-7

183. David AL, Torondel B, Zachary I, Wigley V, Abi-Nader K, Mehta V, et al. Local delivery of VEGF adenovirus to the uterine artery increases vasorelaxation and uterine blood flow in the pregnant sheep. Gene Ther. (2008) 15:1344-50. doi: 10.1038/gt.2008.102

184. Carr DJ, Wallace JM, Aitken RP, Milne JS, Martin JF, Zachary IC, et al. Peri- and postnatal effects of prenatal adenoviral VEGF gene therapy in growth-restricted sheep. Biol Reproduct. (2016) 94:142. doi: 10.1095/biolreprod.115.133744

185. Kane AD, Herrera EA, Camm EJ, Giussani DA. Vitamin C prevents intrauterine programming of in vivo cardiovascular dysfunction in the rat. Circul J. (2013) 77:2604-11. doi: 10.1253/circj.CJ-13-0311

186. Miller SL, Yawno T, Alers NO, Castillo-Melendez M, Supramaniam VG, VanZyl N, et al. Antenatal antioxidant treatment with melatonin to decrease newborn neurodevelopmental deficits and brain injury caused by fetal growth restriction. J Pineal Res. (2014) 56:283-94. doi: 10.1111/jpi. 12121

187. Gonzalez-Candia A, Veliz M, Araya C, Quezada S, Ebensperger G, SeronFerre M, et al. Potential adverse effects of antenatal melatonin as a treatment for intrauterine growth restriction: findings in pregnant sheep. Am J Obstetr Gynecol. (2016) 215:245.e1-7. doi: 10.1016/j.ajog.2016.02.040

188. Hobson SR, Gurusinghe S, Lim R, Alers NO, Miller SL, Kingdom JC, et al. Melatonin improves endothelial function in vitro and prolongs pregnancy 
in women with early-onset preeclampsia. J Pineal Res. (2018) 65:e12508. doi: 10.1111/jpi.12508

189. Astorga CR, Gonzalez-Candia A, Candia AA, Figueroa EG, Canas D, Ebensperger G, et al. Melatonin decreases pulmonary vascular remodeling and oxygen sensitivity in pulmonary hypertensive newborn lambs. Front Physiol. (2018) 9:185. doi: 10.3389/fphys.2018.00185

190. Torres F, Gonzalez-Candia A, Montt C, Ebensperger G, Chubretovic M, Seron-Ferre $\mathrm{M}$, et al. Melatonin reduces oxidative stress and improves vascular function in pulmonary hypertensive newborn sheep. J Pineal Res. (2015) 58:362-73. doi: 10.1111/jpi.12222

191. Thangaratnarajah C, Dinger K, Vohlen C, Klaudt C, Nawabi J, Lopez Garcia $\mathrm{E}$, et al. Novel role of NPY in neuroimmune interaction and lung growth after intrauterine growth restriction. Am J Physiol. (2017) 313:L491-1506. doi: 10.1152/ajplung.00432.2016

192. Welin AK, Svedin P, Lapatto R, Sultan B, Hagberg H, Gressens P, et al. Melatonin reduces inflammation and cell death in white matter in the midgestation fetal sheep following umbilical cord occlusion. Pediatr Res. (2007) 61:153-8. doi: 10.1203/01.pdr.0000252546.20451.1a

193. Yawno T, Mahen M, Li J, Fahey MC, Jenkin G, Miller SL. The beneficial effects of melatonin administration following hypoxia-ischemia in preterm fetal sheep. Front Cell Neurosci. (2017) 11:296. doi: 10.3389/fncel.2017.00296

194. Miller SL, Yan EB, Castillo-Melendez M, Jenkin G, Walker DW. Melatonin provides neuroprotection in the late-gestation fetal sheep brain in response to umbilical cord occlusion. Dev Neurosci. (2005) 27:200-10. doi: 10.1159/000085993

195. Castillo-Melendez M, Yawno T, Sutherland A, Jenkin G, Wallace EM, Miller SL. Effects of antenatal melatonin treatment on the cerebral vasculature in an ovine model of fetal growth restriction. Dev Neurosci. (2017) 39:323-37. doi: 10.1159/000471797

196. Hobson SR, Lim R, Gardiner EE, Alers NO, Wallace EM. Phase I pilot clinical trial of antenatal maternally administered melatonin to decrease the level of oxidative stress in human pregnancies affected by pre-eclampsia (PAMPR): study protocol. BMJ Open (2013) 3:e003788. doi: 10.1136/bmjopen-2013-003788

197. Somm E, Larvaron P, van de Looij Y, Toulotte A, Chatagner A, Faure $\mathrm{M}$, et al. Protective effects of maternal nutritional supplementation with lactoferrin on growth and brain metabolism. Pediatr Res. (2014) 75:51-61. doi: 10.1038/pr.2013.199
198. Gumus HG, Illa M, Pla L, Zamora M, Crispi F, Gratacos E. Nutritional intra-amniotic therapy increases survival in a rabbit model of fetal growth restriction. PLoS ONE (2018) 13:e0193240. doi: 10.1371/journal.pone.0193240

199. Jahan M, Kracht S, Ho Y, Haque Z, Bhattachatyya BN, Wynn PC, et al. Dietary lactoferrin supplementation to gilts during gestation and lactation improves pig production and immunity. PLOS ONE (2017) 12:e0185817. doi: 10.1371/journal.pone.0185817

200. Manzoni P, Rinaldi M, Cattani S, Pugni L, Romeo MG, Messner H, et al. Bovine lactoferrin supplementation for prevention of late-onset sepsis in very low-birth-weight neonates: a randomized trial. JAMA (2009) 302:14218. doi: 10.1001/jama.2009.1403

201. van de Looij Y, Ginet V, Chatagner A, Toulotte A, Somm E, Huppi PS, et al. Lactoferrin during lactation protects the immature hypoxic-ischemic rat brain. Ann Clin Transl Neurol. (2014) 1:955-67. doi: 10.1002/acn3.138

202. Ginet V, van de Looij Y, Petrenko V, Toulotte A, Kiss J, Huppi PS, et al. Lactoferrin during lactation reduces lipopolysaccharide-induced brain injury. BioFactors (2016) 42:323-36. doi: 10.1002/biof.1278

203. Illa M, Brito V, Pla L, Eixarch E, Arbat-Plana A, Batalle D, et al. Early environmental enrichment enhances abnormal brain connectivity in a rabbit model of intrauterine growth restriction. Fetal Diagn Ther. (2017) 44:184-93. doi: 10.1159/000481171

204. James JL, Srinivasan S, Alexander M, Chamley LW. Can we fix it? Evaluating the potential of placental stem cells for the treatment of pregnancy disorders. Placenta (2014) 35:77-84. doi: 10.1016/j.placenta.2013. 12.010

Conflict of Interest Statement: The authors declare that the research was conducted in the absence of any commercial or financial relationships that could be construed as a potential conflict of interest.

Copyright (C) 2019 Malhotra, Allison, Castillo-Melendez, Jenkin, Polglase and Miller. This is an open-access article distributed under the terms of the Creative Commons Attribution License (CC BY). The use, distribution or reproduction in other forums is permitted, provided the original author(s) and the copyright owner(s) are credited and that the original publication in this journal is cited, in accordance with accepted academic practice. No use, distribution or reproduction is permitted which does not comply with these terms. 